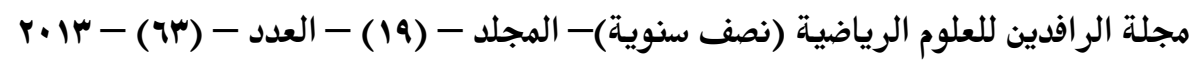

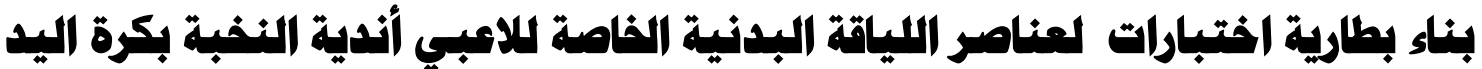

أ. م. دـ سعد باسم جميل" السيد بلال عبد الكريم خضر السيد كرم عبد الكريم خليل

"فرع الالعاب الفرقية/كلية التربية الرياضية/جامعة الموصل/العراق/البريد الاكتروني: Sd_france12@yahoo.com

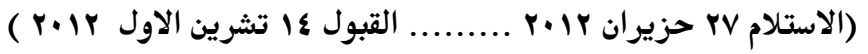

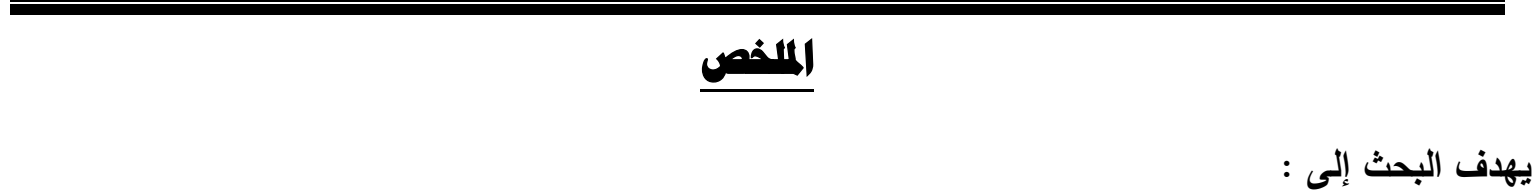

- التعرف على عوامل عناصر اللياقة البذنية الخاصة للاعبي أندية دوري النخبة العراقي بكرة اليل .

- - بناء بطارية اختبار لعناصر اللياقة البدنية الخاصة للاعبي أندية دوري النخبة بكرة اليد.

أما مجالات البحث فقد اشتملت على :

- - المجال البشري : لاعبو أندية (الفتوة والكرخ والجيش والثرطة والكوفة) . -

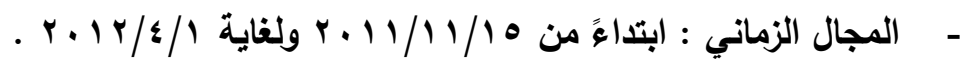

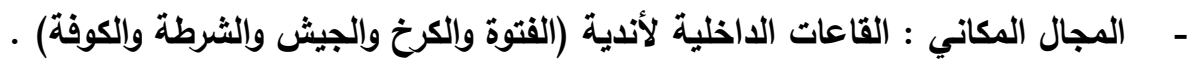

وأستخدم الباحثون المنهج الوصفي بالأسلوب ألارتباطي لملائمته و طبيعة البحث، وتمثل مجتمع البحث بلاعبي أندية

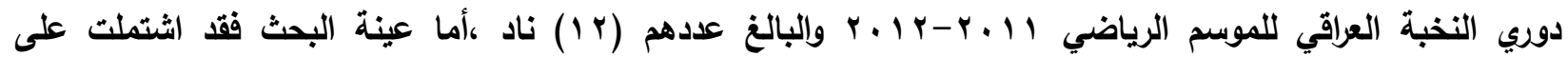

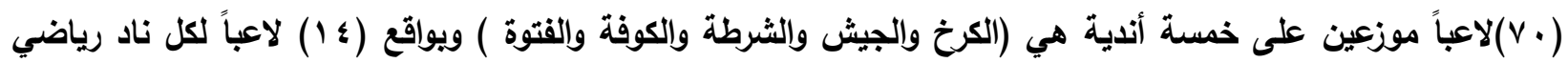

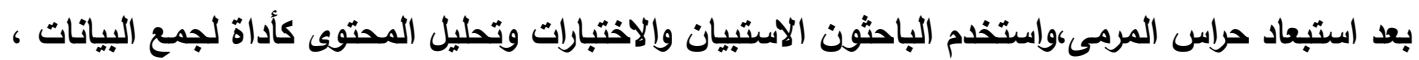

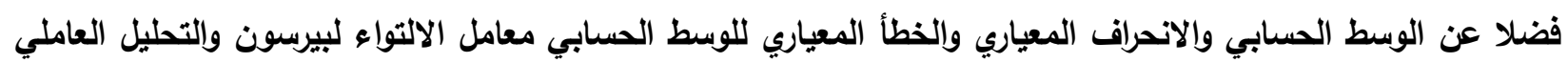
بطريقة المكونات الأساسية (لهوتلنج) باستخدام التدوير المتعامد . ماسطيط

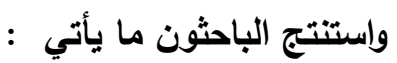
أولا :التحليل ألعاملي باستخدام التذوير المتعامد الذي اجري على (1) اختباراً للياقة البذنية الخاصة تمثل العوامل الافتراضية الستة للياقة البدنية الخاصة ـ اظهر خمسة عوامل تم قبولها في ضوء شروط قبول العامل وهي (العامل الأول عامل السرعة الانتقالية ، العامل الثاني عامل القوة الانفجارية للرجلين ، العامل الثالث عامل القوة الانفجارية

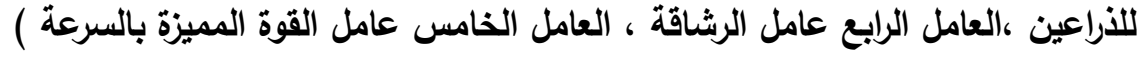
ثانياً : تم استخلاص بطارية اللياقة البذنية الخاصة في ضوء عواملها المستخلصة في هذا البحث التي حققت وحداتها أعلى التى

$$
\begin{aligned}
& \text { التشبعات على العوامل وهي : } \\
& \text { أ- اختبار ركض . . r متر . } \\
& \text { ب - اختبار القفز العمودي . }
\end{aligned}
$$

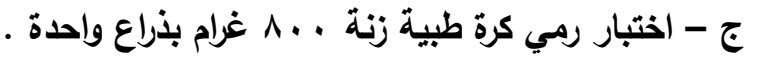$$
\text { د - اختبار جري (الزكزاك) بين الحواجز بالأرقام • }
$$

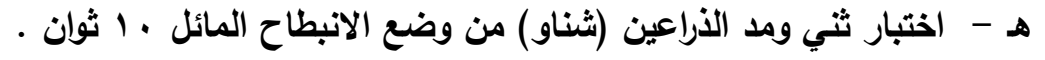

ثالثاً : الوحدات الخمس المختارة لبطارية اللياقة البلينة الخاصة تعد مقاييس خالصة نقية إذ إن تثبعاتها على العوامل الأخرى قريبة من الصفر ويؤكد هذا الاستخلاص انخفاض الارتباطات البينية بين الاختبارات . وأوصى الباحثون بما يأتي : 
استخدام بطارية اللياقة البلنية الخاصة في الاختبارات العملية لمعرفة فاعلية البرنامج التذريبي في نهاية الإعداد

البدني الخاص لأندية كرة اليد العراقية .

الكلمات المفتاحية: بناء بطارية اختبارت - اللياقة البلنية- كرة البلائ

\section{Constructing a Battery of Physical Fitness Elements of Special for the Players}

of Elite Handball Clubs

Assist.Prof. Saad Basim Jamil Mr. Bilal Abul-Karim Khudhr Mr. Karam A. Khalil

\section{$\underline{\text { Abstract }}$}

The research aims at :

- Recognizing the factors of the special physical fitness elements for Iraqi elite clubs players.

- Constructing a battery of special physical fitness elements for the players of elite handball clubs.

The research fields includes :

- Human scope : The players of (Al-Futwa, Al-Karkh, Al-Jaish, Al-Shurtta and Al-Kufa )clubs.

- Time scope : The period between (15/11/2011) to (1/4/2012).

- Place scope : Indoor halls of (Al-Futwa, Al-Karkh, Al-Jaish, Al-Shurtta and Al-Kufa )clubs.

The researchers have adopted the descriptive methodology with the correlation style for its convenience to the nature of the research. The research community has been represented by the players of Iraqi elite tournament clubs (term 2011-2012) which were (12) clubs. While the research sample included (70) players divided into five clubs (Al-Futwa, Al-Karkh, Al-Jaish, Al-Shurtta and Al-Kufa), who represent (14) players for each club after excluding the goal keepers. The researchers have used a questionnaire, tests and the content analysis as a tool of collecting data.

The researchers have used the arithmetic mean, standard deviation, the standard error of the arithmetic mean, coefficient of skewenss (Person), and the coefficient analysis by the method of the essential components of Hottling by using the orthogonal rotation.

The researchers have concluded the following :

1. The coefficient analysis by using the orthogonal rotation performed on (18) tests of special physical fitness representing the six assumption factors of the special physical fitness.It shows five factors accepted in terms of factor acceptance, which are :The first factor is the transitional speed factor, the second is the explosive force factor for the legs, the third is the explosive force factor of the arms, the fourth is the fitness factor, and the fifth factor is the force factor discriminated by speed.

2. The special physical fitness battery has been obtained in the light of its accessed factors whose units achieve highest saturations on the factors, which were:

a- Test of 30m. run.

b- Vertical jump test

$c$ - Test of throwing medicine ball (800gm.) with one arm.

$d$ - Test of zigzag run between barriers with numbers.

$e$ - Test of push up (10 seconds).

3. The fifth units selected for the special physical fitness are considered pure scales for their saturations on the other factors are about to be zero. This result confirms the decrease of the correlation among tests.

The researchers have recommended : 
- Using the battery of the special physical fitness in the practical tests to recognize the training program activity at the end of the special physical preparation for Iraqi handball clubs.

Keywords: Constructing a Battery- - Fitness Elements - Handball

$$
\text { 1- } 1 \text { - التعريف بالبحثة المقدمة وأهمية البحث: }
$$

يتميز عصرنا بالحركة والتطور السريع ونجد كثيرا من الدول الآن تعتمد في تقدمها وتطورها على إتباع

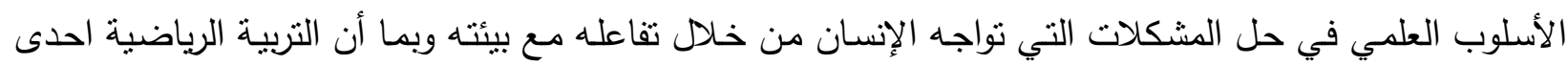

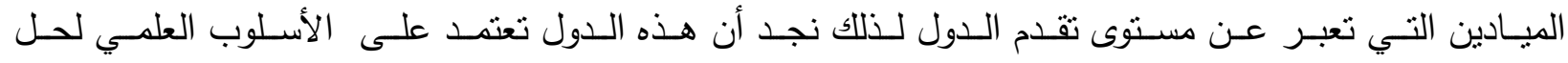
مشـكلاتها،ولكون الاختبـارات والقياسـات احدى الوسـائل العلميـة الضـرورية لاستمرار التقدم العلمي كـان لابـد مـن الاستفادة منها للنهوض بأية لعبة، إذ تعد المحك الموضوعي الذي بواسطته يتم تقويم مناهج التدريب وتقويم كفاءة الطالب، حيث يعد الاختبار والقياس الوسيلة التي يمكن الوقوف من خلالها على حالة اللاعب البدنية أو المهارية أو لوابه مايخص أي محدد أخر يؤثر في مستوى الأداء، لذلك تفنن المختصون بوضـع الاختبارات أو القياسات المناسبة بكل مجال من مجالات التربية الرياضية على أن الاختبارات لا تخرج عن كونها إما ذاتية تعتمد على الخبرات الثخصية والمعايير الذاتية أو موضوعية باستخدام وحدات قياس متعارف عليها ولا يمكن أن يختلف عليها اثتان، ويميل العالم الآن إلى استخدام الاختبارات الموضعية لما تمناز من دقة الحصول على النتائج وعدم تدخل مؤثز خارجي، ولاسيما في قياس عناصر اللياقة البدنية والمهارات للألعاب الرياضية من خلال وحدات القياس الموضعية كوحدات (التكرار أو الدرجة أو الزمن أو المسافة)

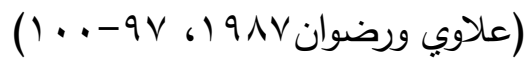

وتعد كرة اليد من الأنشطة الرياضية التي تتطلب ممارستها أداء مهارات ذات مواصفات معينة وتكتيك فني

دقيق يحتاج إلى إمكانات حركية ومتطلبات خاصـة لأدائها، لذا زاد اهتمام الباحثين والمهتمين بلعبة كرة اليد ببحث

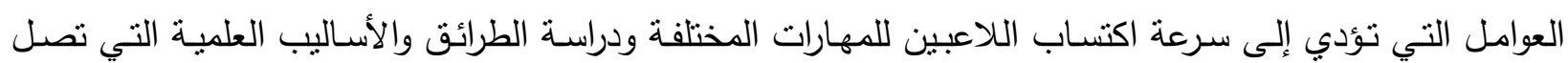
باللاعب إلى الأداء الأمثل، وعلى الرغم من أن بحوثاً ودراسات عديدة أجريت في هذا المجال إلا أن لعبة كرة اليد مازالت تفتقر للعديد من بطاريات الاختبار مقارنة بالبطاريات العديدة التي شملت اللياقة البدنية والألعاب الجماعية الأخرى وتبعاً لذلك فأن كرة اليد بحاجة إلى كثير من الاختبارات ذات الثقل العلمي المستتد إلى الأساليب الإحصائية

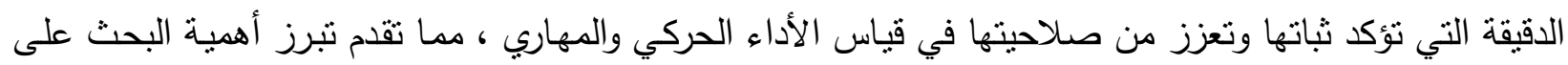

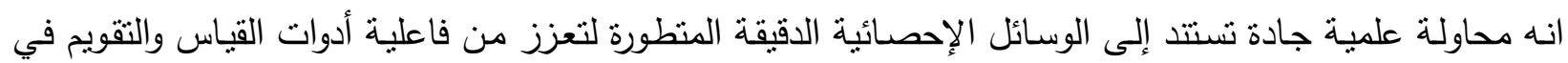

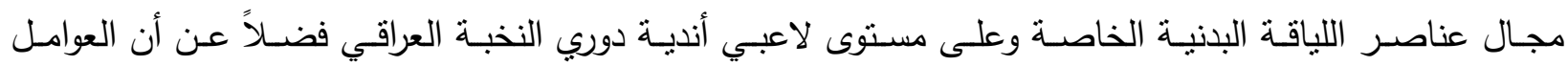
المستخلصة من هذه الدراسة سوف تعكس الواقع الفعلي لقدرات لاعبي أندية النخبة العراقي في مجال العناصر اللياقة البدنية التي يتمتعون بها. r- r r r مشكلة البحث

من خلال متابعة الباحثون لمباريات كرة اليد العالمية لوحظ التأثير الكبير لعناصر اللياقة البدنية والتي تلعب دوراً كبيراً في اغلب الأحيان في نتائج المباريات والتي يظهر تأثثرها واضحا ولاسيما في الدقائق الأخيرة من المباراة والتي تعطي لاعبي الفريق الذي يتمتع بلياقة عالية الغلبة على الفريق الخصم ، وعلى حد علم الباحثون انه لا توجد 
دراسة تتاولت عناصر اللياقة البدنية الخاصة وعلى لاعبي دوري النخبة العراقي بكرة اليد من هنا تبرز مشكلة البحث

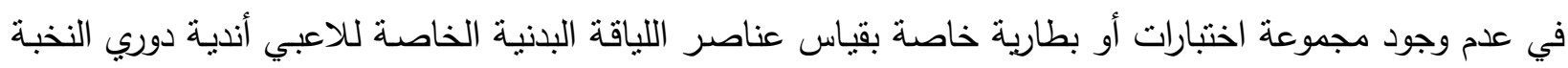
العراقي.

\section{ا}

1-r-1 التعرف على عوامل عناصر اللياقة البدنية الخاصة للاعبي أندية دوري النخبة العراقي بكرة اليد . 1-r-r-r بناء بطارية اختبار لعناصر اللياقة البدنية الخاصة للاعبي أندية دوري النخبة بكرة اليد.

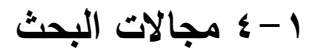

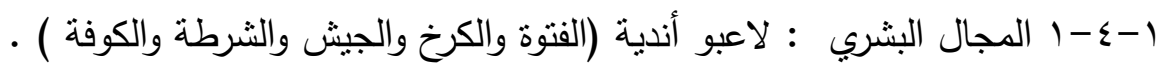

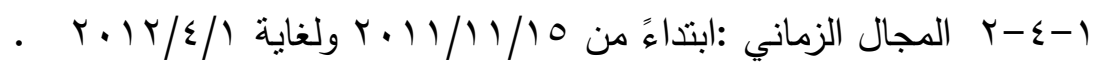

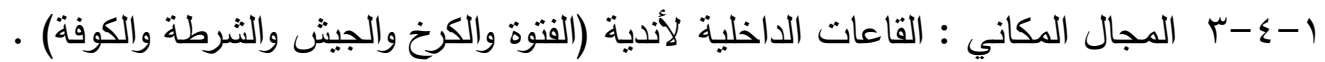
r - ب الإطار النظري والدارات السابقة ب-1-1 اللياقة البدنية في كرة اليد اللياقة البننية مصطلح اهتم به العديد من الباحثين في مجال التربية الرياضية للاستفادة منه والبحث عن

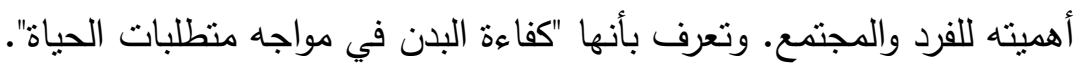

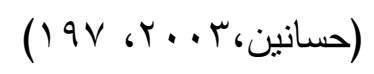

ولعناصر اللياقة البدنية الدور المؤثر والمهم في فعالية الأداء المهاري، فكلما تحسنت صفات القوة والسرعة و المطاولة والمرونة نصل إلى مستوى مهاري جيد.

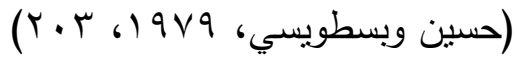

وكرة اليد هي من إحدى هذه الألعاب الني تحتاج إلى لياقة بدنية عالية ، لأن صغر مساحة الملعب وسرعة

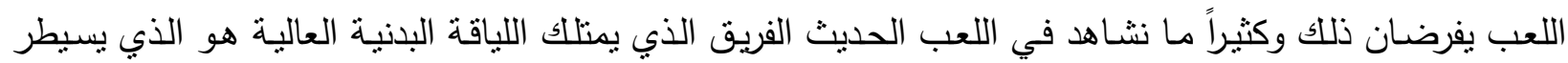
على المباراة من البداية الى النهاية. وهناك علاقة قوية بين الدهارات الحركية الرياضية لكرة اليد واللياقة البدنية. فأداء

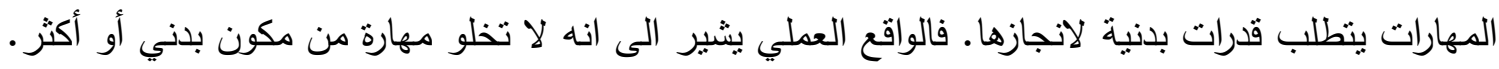

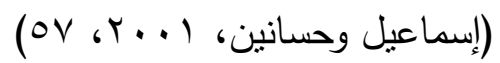

r-r-r r-r

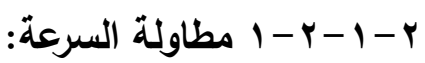

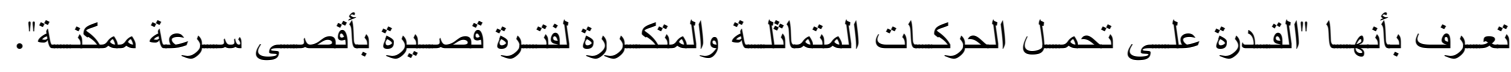

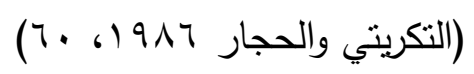

وتظهر حاجة لاعب كرة اليد إلى مطاولة السرعة لكي يتمكن من أداء حركات سريعة كلما تطلب الأمر ذلك طوال

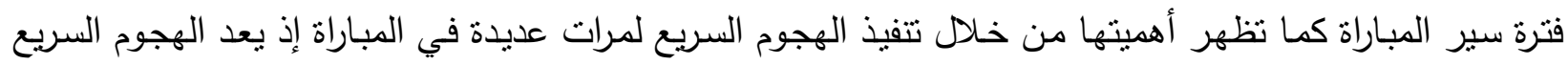

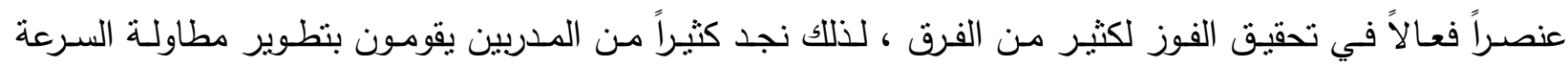

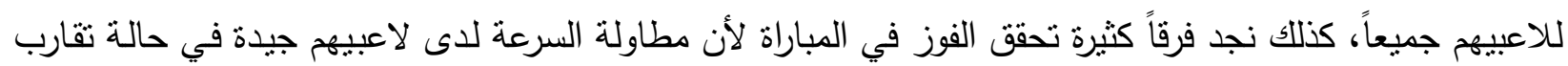

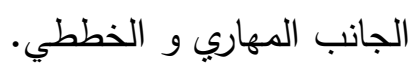


إن

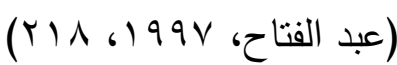

تعرف بأنها قدرة الفرد على تغيير أوضاعه في الهواء.

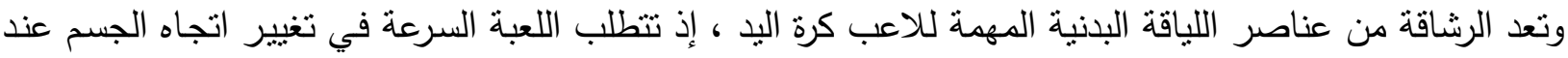

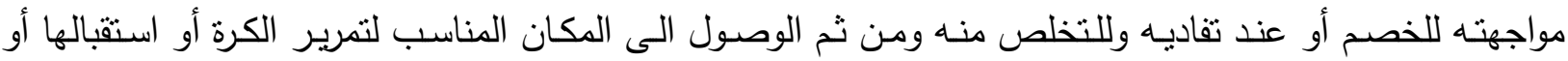

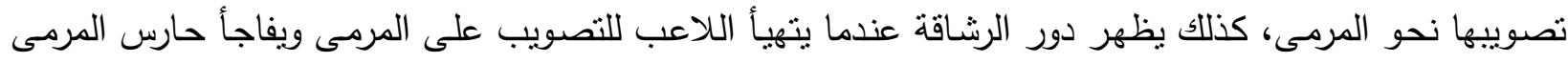

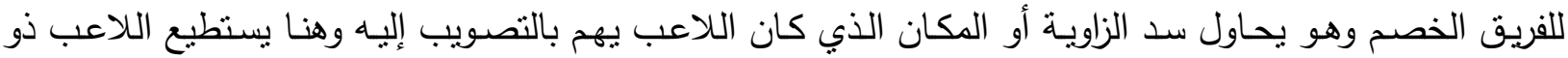

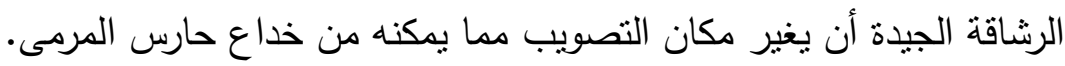

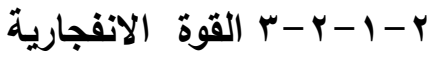
وتعرف بأنها "قابلية رمي اكبر كمية من القوة العضلية العضية في اقل زمن ممكن".

(حسين وبسطويسي، 19 (111،

والقوة الانفجارية ضرورية للاعب كرة اليد ، فالقفز للتمرير إلى زميل أو للتصويب على المرمى ضرورة لكل

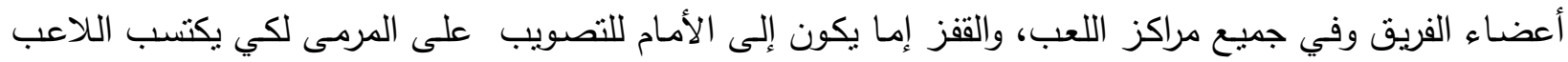

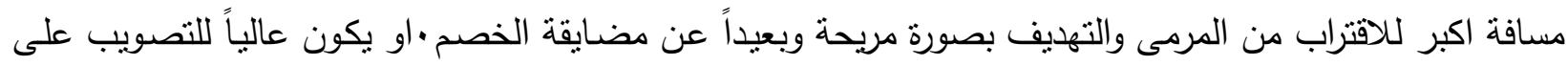

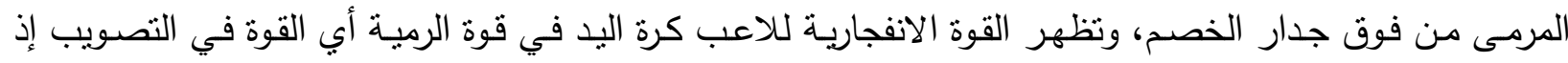

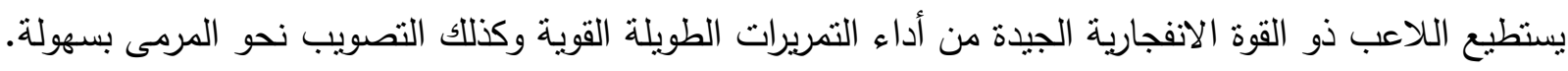

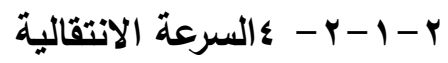

تعرف بأنها الانتقال من مكان إلى آخر بأقصى سرعة ممكنة أي التغلب على مسافة معينة بأقصى زمن

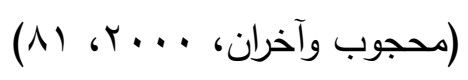

ممكن.

وتظهر حاجـة لاعب كرة اليد إلى السرعة الانتقالية من خـلال حركته داخل حدود الملعب وأثـغاله المكان

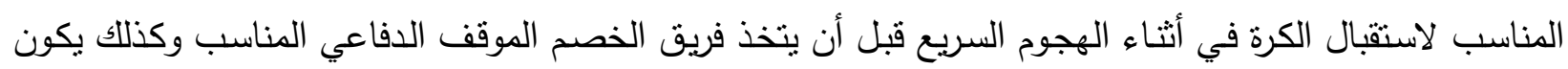

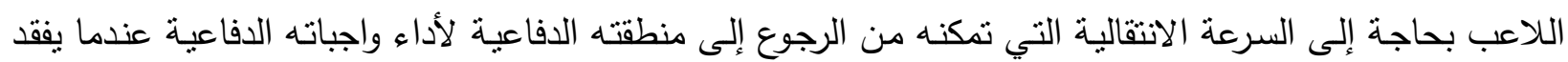

فريقه الكرة.

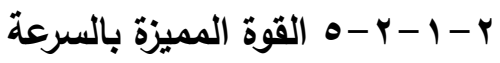

تعرف بأنها صفة بدنية مركبة من صفتي القوة والسرعة وتحتاج إليها الكثير من الأنثطة والفعاليات الرياضية التي

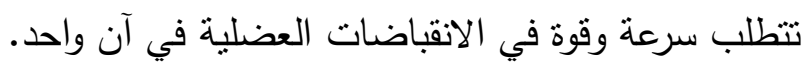

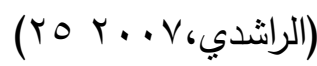

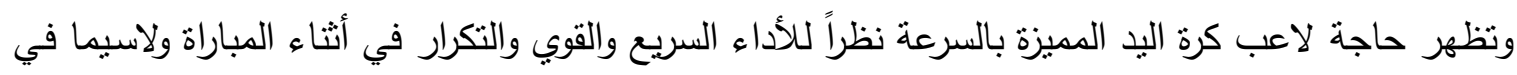

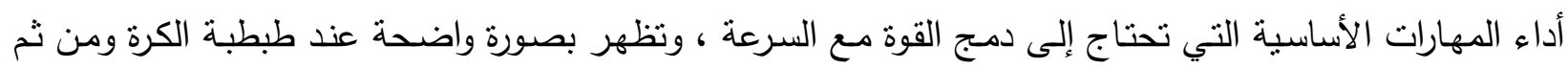
تمريرها وأداء الخداع فضلاً عن الانطلاق والتوقف الكفاجئ ألثاء الثباء المباراة. 
( درالبة

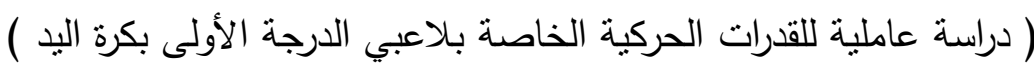

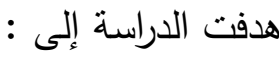

- التعرف على ارتباط القدرات الخاصة للاعبي الدرجة الأولى بكرة اليد . - انتقاء وتقتين مجموعة من الاختبارات لقياس القدرات الحركية الخاصة للاعبي كرة اليد. - تحديد أفضل الاختبارات لقياس القدرات الحركية الخاصة للاعبي الدرجة الأولى بكرة اليد.

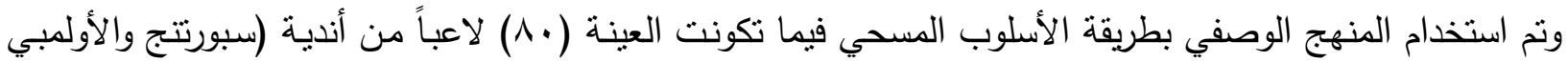

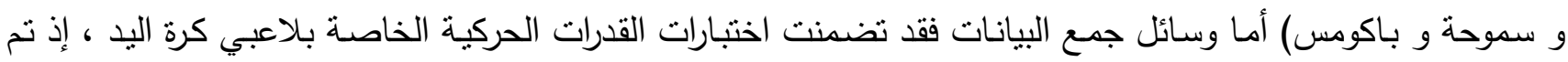
ترشيح (07) اختبار وقد تم تطبيق تجربتين استطلاعيتين للحصول على الأسس العلمية للقدرات المرشحة تلا ذلك التطبيق النهائي على عينة البحث وتضمنت الوسائل الإحصائية التحليل العاملي بطريقة المكونات الرئيسة ، كما تم استخدام طريقة

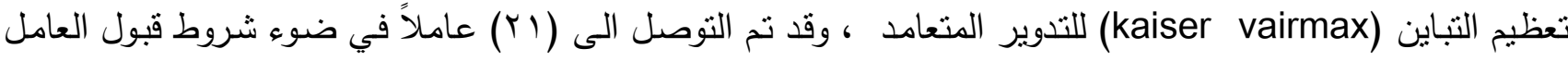

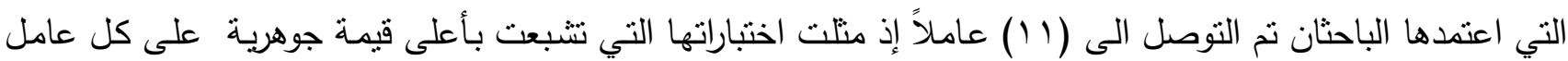

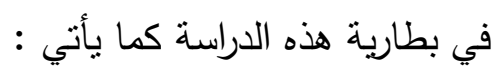
العامل الأول (النوافق بين العين واليد) واختباره تمرير كرة اليد على الحائط لمدة دقيقة والعامل الثاني (المرونة الديناميكية)

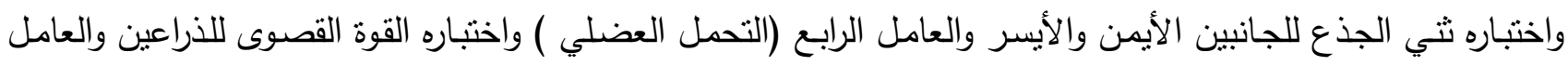

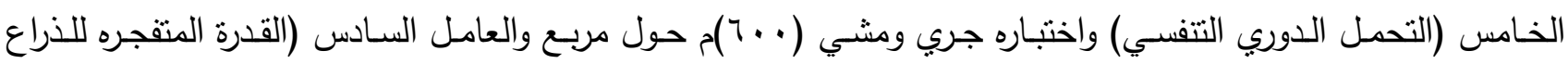

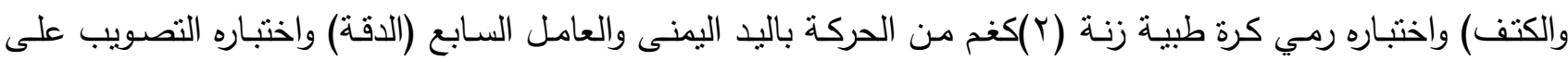

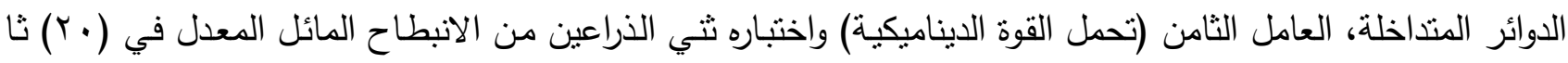
و العامل التاسـع (النوازن الحركي) واختباره المشي على عارضـة التوازن و العامل الثاني عثر (السرعة الانتقاليـة)

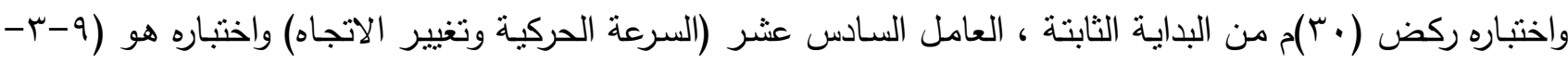
ج-r-9) ، العامل الثامن عثر (الدقة وسرعة الأداء) واختباره التصويب على دائرة واحدة في دقيقة.

$$
\text { r- r- إجراءات البحث }
$$

استخدم الباحثون المنهج الوصفي بالأسلوب ألارتباطي لملائمته وطييعة البحث.

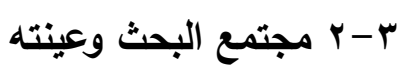

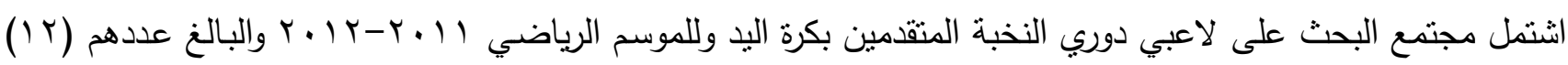

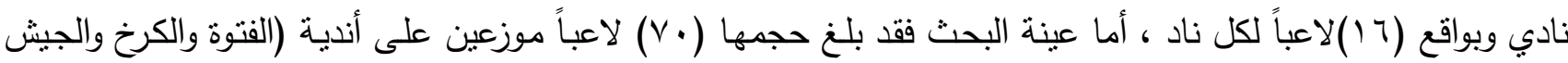

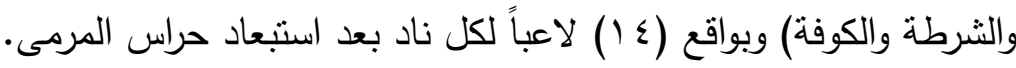

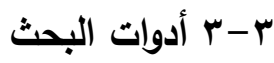
تم استخدام تحليل المحتوى والاستيان والاختبارات كأدوات للبحث . م البـ 
r-r-

اعد الباحثون استمارة الاستبيان كما في الملحق (1) وتم عرضهـا على مجموعة من المختصين* ، ومن اجل الحصول على عناصر اللياقة البدنية الخاصـة في كرة اليد قام الباحثون بالمستح الثـامل للمصادر العلمية ومنها (الأبحر

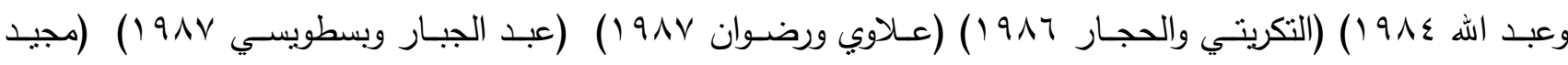
1919 جr) (حسانين (990) (حسـانين (997) ) ، وقد تم الاتفاق على جميع العناصر التي حددها الباحثون والتي عرضت على السادة المختصين وكما في الملحق (Y) : r- الأجهزة والأدوات المستخدمة

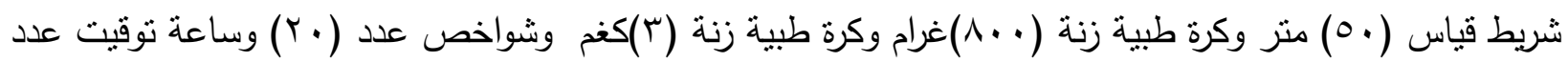

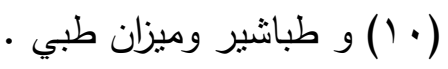
بـ إن التجارب الاستطلاعية

نظراً لخصوصية الدراسة في كونها دراسة عاملية تتطلب تحليل عدد كبير من الاختبارات ذات شروط ومواصفات علمية محددة ، فقد قام الباحثون بإجراء بعض التجارب الاستطلاعية وبمساعدة فريق العمل المساعد* *، وقد كان لكل تجربـة

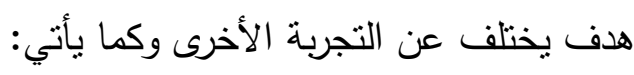
r- - التجربة الاستطلاعية الأولى

أجريت التجربـة الاستطلاعية الأولى على عينـة مؤلفة من (• ( ) لاعبين من نـادي الفتوة الرياضـي اختبر أفرادها

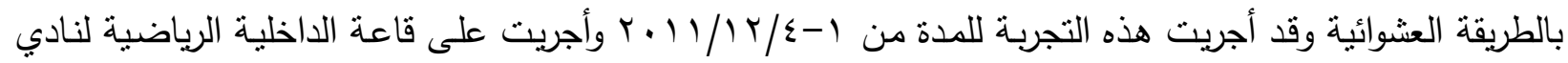

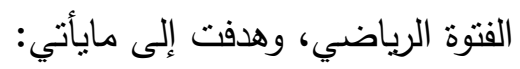
- تحديد المدة الزمنية التي ستستغرقها الاختبارات بصورة عامة . - إمكانية فريق العمل المساعد - مدى كفاءة الأجهزة والأدوات المستخدمة .

كلية التربية الرياضية / جامعة الموصل كلية التربية الرياضية / جامعة الموصل الماضية الماضية الموصل كلية التربية الرياضية /جامعة الموصل كلية التربية الرياضية / جامعة الموصل / جامية الموصل كلية التربية الرياضية / جامعة الموبية الموصل كلية التربية الرياضية / جامعة التربية الموصل

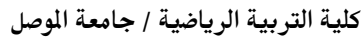
كلية التربية الرياضة / جامعة المباضية الموصل

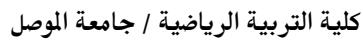
كلية التربية الرياضية / جامعة الموصل
لاعب نادي الكرخ الرياضي

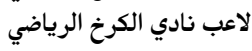

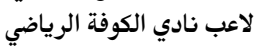

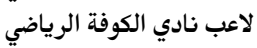

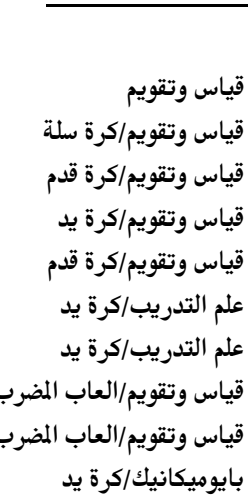

* السادة المختصين أ.د ثيلام يونس علاوي أ. أ. هاشم احمد بوند سليمان أ. أ.د مكي محمود حسين احمد سليمان أ. أ. عبد الكريم مجمود حساسم أ. أ.د ضرغام جاسم محمد أ.م.د نوفل محمد محمود

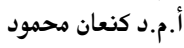
أ. أ.م.د ايثار عبد الكريم أ. أ.م.د سبهـان محمود عيدار الكريم أ.م.د محمد خليل

\begin{tabular}{|c|c|}
\hline \multicolumn{2}{|c|}{ *** فريق العمل المساعد } \\
\hline خريج كلية التربية الرياضية & عمار هذال \\
\hline خريج كلية الاداره الاقتصاد & هاني محمد \\
\hline خريج كلية التربية الرياضية & علي باسم \\
\hline طالب كلية التربية الرياضية/جامعة الموصا & مصطفى باسم \\
\hline
\end{tabular}


r-ه-r التجرية الاستطلاعية الثانية (المعاملات العلمية للاختبارات الخاضعة للتحليل) أجريت هذه التجربة على عينة مؤلفة من( • () لاعبين (عينة التجربة الاستطلاعية الأولى نفسها) وقد أجريت هذه

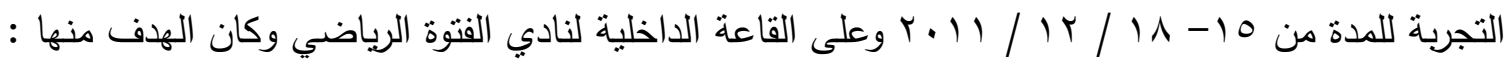
- إيجاد معامل الثبات والحصول على صدق الاختبارات من خلال الصدق الذاتي بإيجاد الجذر التربيعي للتبات وقد اعتمد

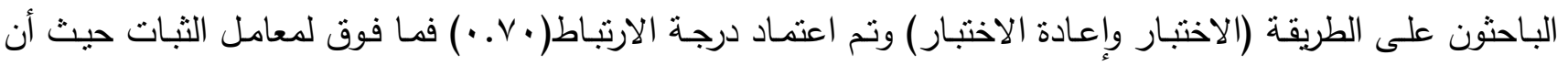

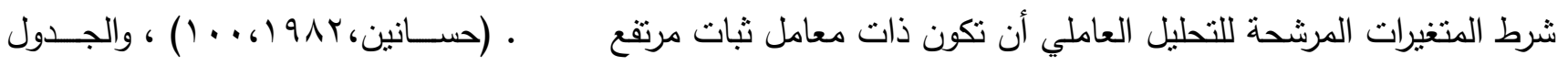
رقم (1) يبين المعاملات العلمية للاختبارات .

الجدول رقم (1)

يبين معامل الثبات والصدق الذاتي لاختبارات عناصر اللياقة البننية الخاصة

\begin{tabular}{|c|c|c|c|c|c|c|c|c|}
\hline \multirow{2}{*}{ 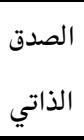 } & \multirow{2}{*}{ معامل } & \multicolumn{2}{|c|}{ 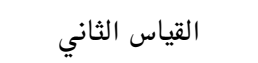 } & \multicolumn{2}{|c|}{ 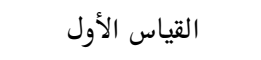 } & \multirow{2}{*}{ 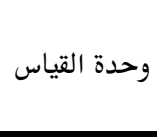 } & \multirow{2}{*}{ اسم الاختبار } & \multirow{2}{*}{$ت$} \\
\hline & & $\varepsilon^{ \pm}$ & 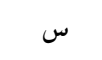 & $\varepsilon^{ \pm}$ & $\bar{\omega}$ & & & \\
\hline$\cdot .9 \leqslant$ & $\cdot \triangleleft \wedge \wedge$ & $r_{6} \cdot 1$ & $\Delta Y \cdot \wedge \varepsilon$ & $r, r V$ & $0 Y 679$ & ثانيه & ركض · · م متر & -1 \\
\hline .69 & . & $r_{6} \cdot \varepsilon$ & 70.07 & $r_{6} .9$ & $7 \leqslant .99$ & ثانيه & ركض · ·ـ متر & $-r$ \\
\hline . .9r & $\cdot ، \wedge$ & 169. & $T V \cdot \Delta \Lambda$ & 1.94 & $M \Lambda, I V$ & ثانيه & الركض بالمواجه والظهر لمسافة ror متر & $-r$ \\
\hline . .9r & $\cdot ، \wedge$ & $|, r|$ & $r r a \xi r$ & $16 \mathrm{rr}$ & rtatr & ثانية & بارو & $-\varepsilon$ \\
\hline .691 & $\cdot ، \wedge r$ & .94 & rrG rl & I.rV & YI. Q 9 S & ثانيه & جري الزكزاك بين الحواجز بالأرقام & -0 \\
\hline .694 & $\cdot \triangleleft \wedge \mathrm{V}$ & .674 & 9.18 & 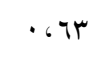 & $96 \cdot 7$ & ثانيه & الجري المكوكي(؛ ××+1) م & -1 \\
\hline .697 & . .9r & r.11 & 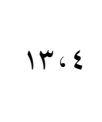 & r. Ir & 1469 & 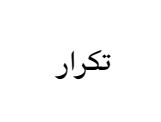 & 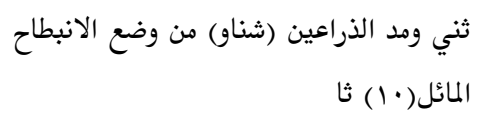 & $-v$ \\
\hline$\cdot 69$ & $\cdot ، \wedge 1$ & $16 \leqslant Y$ & Ir.r & 1.19 & 1469 & 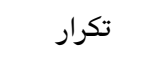 & الجلوس من الرقود مع مد الرجلين (·()ثا & $-\wedge$ \\
\hline .69 & $\cdot \triangleleft \wedge \wedge$ & $\cdot$ Gr & v & $\cdot .111$ & $v_{6} \cdot \wedge$ & 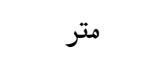 & ثلاث وثبات بالقدمين من الثبات & -9 \\
\hline .697 & $.69 r$ & $.61 r$ & 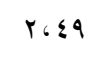 & .6 .9 & Y.o & ثانيه & ركض •r متر & -1 \\
\hline$\cdot 694$ & $\cdot \triangleleft \wedge \vee$ & .611 & r.o. & $\cdot 61$ & $\mu, \leqslant 0$ & ثانيه & ركض ·r متر & -11 \\
\hline .69 & $\cdot \triangleleft \wedge \vee$ & $\cdot .14$ & $\leqslant$ : 0 & .61 & $\varepsilon$. $\leqslant 0$ & ثانيه & ركض · ؛ متر & $-i r$ \\
\hline .690 & $\cdot 69$ & $r_{6} \cdot r$ & or.o & E,rt & V.V V & 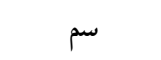 & 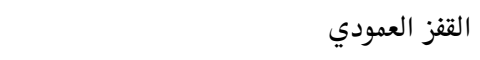 & -14 \\
\hline$\cdot .9 \varepsilon$ & $\cdot \triangleleft \wedge \wedge$ & 167 & $r, \varepsilon$ & $1 . \mathrm{V}$ & r.o & 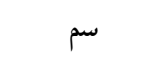 & القفز العريض & $-1 \varepsilon$ \\
\hline $.69 V$ & .69 & $116 . r$ & rAYro & 10.9 & rAo, & 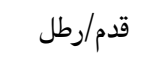 & القدرة العمودية (الشغل) & -10 \\
\hline .69 & $\cdot \triangleleft \wedge \wedge$ & .611 & 7.95 & $\cdot$. rVo & $V_{6} \cdot r$ & 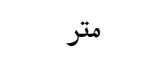 & رمي كرة الطبية (r) كغم من الجلوس & -17 \\
\hline $.69 r$ & $\cdot \triangleleft \wedge \varepsilon$ & $\cdot r \mathrm{rV}$ & 11618 & 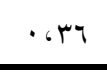 & $11 . r$ & 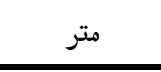 & رمي كرة الطبية (rّ) كغم من الجلوس & $-1 \mathrm{n}$ \\
\hline .997 & . . 94 & 1.7 & roso & $1 . \mathrm{V}$ & ro.s & متر & رمي كرة الطبية (·^) غرام بذراع واحدة & -11 \\
\hline
\end{tabular}


ب- ب- التجرية الأساسية (النهائية)

بعد أن أكدت التجربتان الاستطلاعيتان الأولى والثانيـة صـلاحية الاختبـارات (1/) مـن خـلال إيجـاد

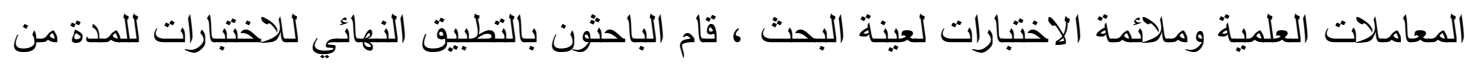

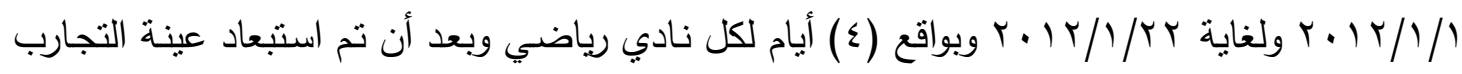

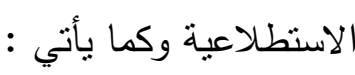

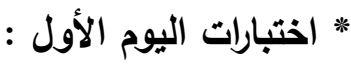
ركض · آمتر وثثي ومد الذراعين (شناو) من الانبطاح المائل (· (1) ثوان والقفز العمودي والجري

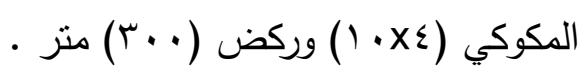

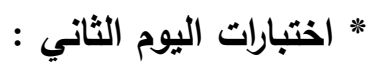

ركض (·r) متر والجلوس من الرقود مـع مد الرجلين (· ( ) ثوان والوثب العريض ورمسي كرة طبية

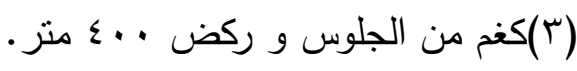

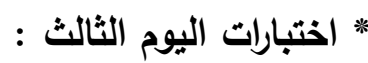

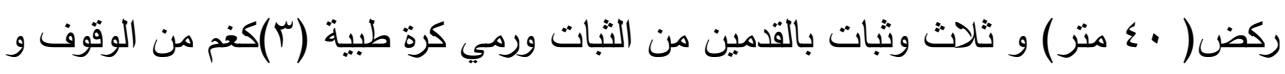

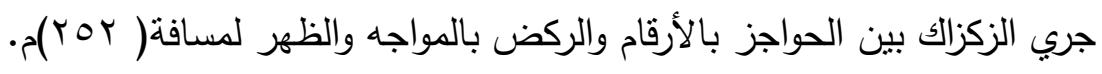

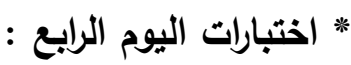

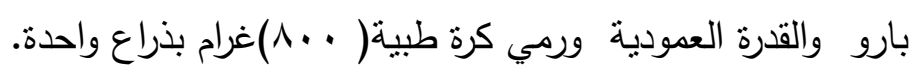

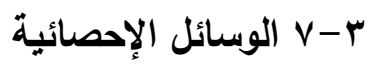
استخدم الباحثون الوسائل الإحصائية الآتية:

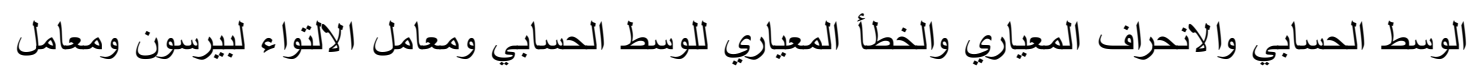
الارتباط البسيط والتحليل العاملي بطريقة المكونات الأساسية لهوتلنج (Hottelling components) باستخدام التدوير المتعامد.

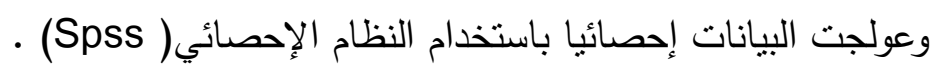
؛ - عرض النتائج وتحليلها ومناقشتها ع - أبارية اللياقة البانية الخاصة ع - 1 - 1 الوصف الإحصائي لاختبارات عناصر اللياقة البذنية الخاصة

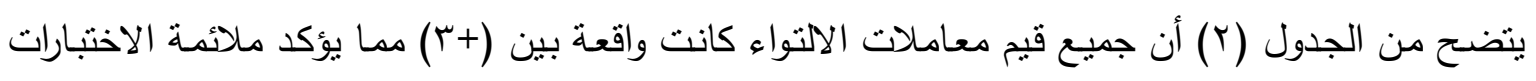

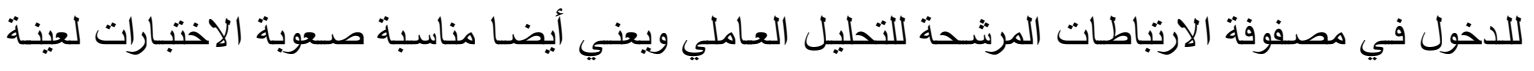

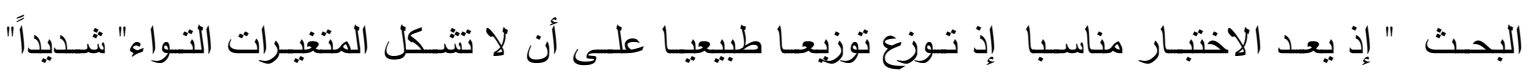

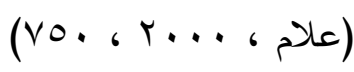
ونلاحظ أن قيم الأوساط الحسابية للمتغيرات جميعها تتجاوز الانحراف المعياري وهذا يثبت ملائمة متغيرات البحث للعينة وصلاحيتها للإدخال ضمن المصفوفة الارتباطية المعدة للتحليل العاملي. 
كما أن قيم الخطأ المعياري منخفضة( اقل من ( ) مما يؤكد مناسبة حجم العينة المنتخبة للتحليل العاملي.

$$
\text { (فرج، • ( }
$$

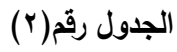

يبين الوصف الإحصائي لاختبارات اللياقة البذنية الخاصة

\begin{tabular}{|c|c|c|c|c|c|c|c|}
\hline 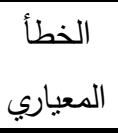 & معامل الالتواء & 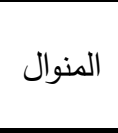 & 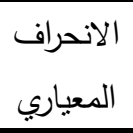 & الوسط الحسابي & وحدة القياس & اسم الاختبار & $ت$ \\
\hline .611 & $\cdot 6 \varepsilon-$ & or.人o & $1 ، \varepsilon r$ & Or.rT & ثانيه & ركض . ..r متر & -1 \\
\hline . Gr & $\cdot ، \varepsilon)$ & $T \varepsilon$ & $16 \mathrm{VT}$ & $T \Sigma, V$ & ثانيه & ركض . . ع منز & $-r$ \\
\hline .617 & .611 & 71,10 & $1, r \varepsilon$ & $7 \Lambda_{6} Y_{9}$ & ثانيه & الركض بالمواجه والظهر لمسافة ror منز & - \\
\hline .614 & $\cdot ، \varepsilon-$ & r r.A. & $.69 Y \leq$ & Mr. $\varepsilon \varepsilon$ & ثانية & بارو & $-\varepsilon$ \\
\hline $.61 \varepsilon$ & . ، & 51.90 & .614 & MrG $\varepsilon r$ & ثنانيه & جري الزكزاك بين الحواجز بالأرقام & -0 \\
\hline .67 & 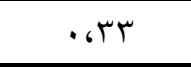 & 1.90 &. ، «^ & 9611 & ثنانيه & الجري المكوكي(ء × ()) م & -7 \\
\hline .6 .9 & $.6 r$. & ir & $.6 V 7 V$ & Trgt & 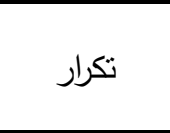 & 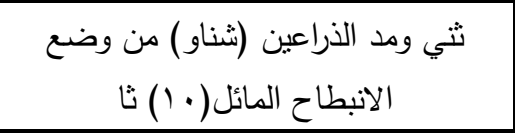 & $-v$ \\
\hline . & $.67 .-$ & ir & 16.4 & IT, Th & 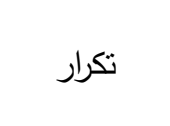 & الجلوس من الرقود مع مد الرجلين (• ( ) & $-\wedge$ \\
\hline .67 & .611 & $v$ & . $₫ \leqslant 0$ & $v_{6} \cdot 1$ & 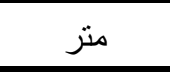 & ثلاث وثبات بالقدمين من الثبات & -9 \\
\hline..$\cdot 1$ & $\cdot ، \wedge$ & r، $\varepsilon$. & $\cdot 6 \cdot 1$ & $r_{6} \leqslant T$ & ثانيه & ركض • r متر & -1 \\
\hline$\cdot . r$ & $.690-$ & r.9. &. Gr & r.79 & ثانيه & ركض •r متر & -11 \\
\hline..$+r$ & $1,4-$ & $\varepsilon .99$ & תזים & $\varepsilon, 71$ & ثنانيه & ركض ·ـ متر & $-1 r$ \\
\hline.$\wedge$ & .64 & 7. & $0.9 \mathrm{~V}$ & 71,4 & 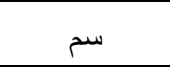 & الققز العمودي & -14 \\
\hline..$r$ & $.6 r-$ & r.o. & .611 & $r_{6} \leqslant T$ & 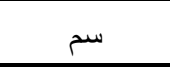 & القفز العريض & $-1 \leqslant$ \\
\hline $1, r \mathrm{~V}$ & $.67-$ & $r \varepsilon$. & 1.67 & TMtrat & قدم/رطل & القدرة العمودية (الثغل) & -10 \\
\hline$\because . \cdot V$ & $.6 r-$ & 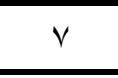 & .00 & 7.99 & منز & رمي كرة الطبية (r) كغم من الجلوس & -17 \\
\hline.. .0 & 1,1 & 11 & $.6 \mathrm{rr}$ & $11 ، \varepsilon$ & 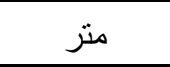 & رمي كرة الطبية (ץ) كغم من الجلوس & $-1 V$ \\
\hline . TO & $.6 \mathrm{Vr}$ & $r \varepsilon$ & 1.9 & ro، & 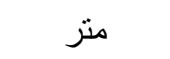 & رمي كرة الطبية (· . ^) غرام بذراع واحدة & -11 \\
\hline
\end{tabular}

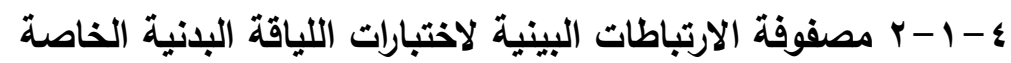

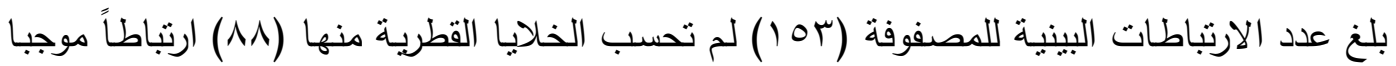

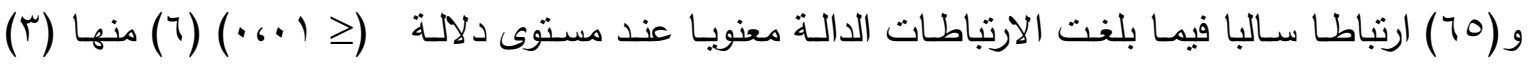

معنوبا موجبا و (r) معنويا سالبا.

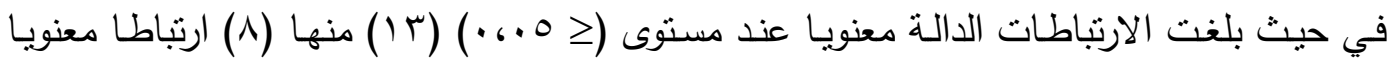

موجبا و(0) ارتباطا معنويا سالبا . 
الجدول رقم (r) يبين معاملات مصفوفة الارتباطات البينية لعناصر اللياقة البنية الخاصة

\begin{tabular}{|c|c|c|c|c|c|c|c|c|c|c|c|c|c|c|c|c|c|c|}
\hline 11 & IV & 17 & 10 & $1 \varepsilon$ & 14 & 14 & 11 & 1. & 9 & $\wedge$ & $v$ & 7 & 0 & $\varepsilon$ & $r$ & $r$ & 1 & ت \\
\hline & & & & & & & & & & & & & & & & & 1 & -1 \\
\hline & & & & & & & & & & & & & & & & 1 & ס ז, . & $-r$ \\
\hline & & & & & & & & & & & & & & & 1 & . GYYT & $\ldots, r$ & $-r$ \\
\hline & & & & & & & & & & & & & & 1 & .6170 & $\ldots$ & .6101 & $-\varepsilon$ \\
\hline & & & & & & & & & & & & & 1 & . YYVA & $.61 \leqslant V$ & $\cdot \sigma \leqslant r$ & $.610 Y$ & -0 \\
\hline & & & & & & & & & & & & 1 & $\begin{array}{c}- \\
.6191\end{array}$ & $\ldots v$. & 0 & $\begin{array}{c}- \\
. ., 0.4\end{array}$ & $\begin{array}{c}- \\
., \cdot r r\end{array}$ & -7 \\
\hline & & & & & & & & & & & 1 & $\begin{array}{c}- \\
.6 r \cdot 7\end{array}$ & . $61 \leqslant 1$ & $\begin{array}{c}- \\
.6 .1\end{array}$ & $\begin{array}{c}- \\
.6 .07\end{array}$ & . TYYA & .611 & $-v$ \\
\hline & & & & & & & & & & 1 & $\because \vee \vee \wedge$ & 0.6. & . . FY &.$r Y \otimes \Lambda$ & $\begin{array}{c}- \\
.6 . r V\end{array}$ & .6 .0$. & $\begin{array}{c}- \\
.6 .74\end{array}$ & $-\Lambda$ \\
\hline & & & & & & & & & 1 & $\begin{array}{c}- \\
.61 V V\end{array}$ & - GYYY & $\begin{array}{c}- \\
.6 .94\end{array}$ & . . &. $.1 r$ & . $61 \leqslant$. & $\ldots \vee \vee q$ & $\begin{array}{c}- \\
.6 .0 \mathrm{~V}\end{array}$ & -9 \\
\hline & & & & & & & & 1 & $\begin{array}{c}- \\
.61 \ldots\end{array}$ & $.61 \leqslant 9$ & $.61 Y A$ & $\begin{array}{c}- \\
.6 .9 \leq\end{array}$ & $\begin{array}{c}- \\
.6 .41\end{array}$ & $\begin{array}{c}- \\
.61 .0\end{array}$ & $\begin{array}{c}- \\
.6 Y 11\end{array}$ & $\begin{array}{c}- \\
.6 .10\end{array}$ & $.61 Y V$ & -1. \\
\hline & & & & & & & 1 & $\cdots v$. & $\begin{array}{c}- \\
.61 Y 0\end{array}$ & \& & $\begin{array}{c}- \\
.6 Y 17\end{array}$ & צ'ים & .6 .11 & $\begin{array}{c}- \\
.610 \leqslant\end{array}$ & . & ه ., . & r... & -11 \\
\hline
\end{tabular}




\begin{tabular}{|c|c|c|c|c|c|c|c|c|c|c|c|c|c|c|c|c|c|c|}
\hline & & & & & & 1 & . $V 99 \vee$ & $\begin{array}{c}- \\
. ., r Y\end{array}$ & $\cdot 6 \cdot \wedge 1$ & $\begin{array}{c}- \\
.6 \cdot V r\end{array}$ & $\begin{array}{c}- \\
., Y 1 .\end{array}$ & . YYAT & $\cdot, \cdot \wedge r$ & $.61 V Y$ & $\begin{array}{c}- \\
\cdot . \cdot 1 .\end{array}$ & $.01 T V$ & .6 .99 & $-1 Y$ \\
\hline & & & & & 1 & .611. & .6 .9$. & r & . & צ'.6. & .6 .01 & $\begin{array}{c}- \\
.6 .7 V\end{array}$ & $\begin{array}{c}- \\
.6 .9 r\end{array}$ & $\begin{array}{c}- \\
.6 \cdot v \theta\end{array}$ & $\begin{array}{c}- \\
., r \wedge r\end{array}$ & $\begin{array}{c}- \\
.617 \varepsilon\end{array}$ & .699 & $-1 \mu$ \\
\hline & & & & 1 & .6100 & $\begin{array}{c}- \\
\cdot \text {. } r \wedge r\end{array}$ & $\begin{array}{c}- \\
.|| r \mid\end{array}$ & 7 & $\begin{array}{c}- \\
.6 \cdot V V\end{array}$ &., 0. & $\cdot 6 \cdot V 0$ & $\begin{array}{c}- \\
.6194\end{array}$ & $\begin{array}{c}- \\
.6 Y V 0\end{array}$ & $\begin{array}{c}- \\
\cdots, \cdot 1\end{array}$ & $\begin{array}{c}- \\
.6 .0 r\end{array}$ & $\begin{array}{c}- \\
.611\end{array}$ & $.6 .1 \mathrm{~V}$ & $-1 \leqslant$ \\
\hline & & & 1 & $.61 r$. & - & $\begin{array}{c}- \\
., \cdot+{ }_{1}\end{array}$ & $\begin{array}{c}- \\
. .+r_{1}\end{array}$ & $\begin{array}{c}- \\
.6179\end{array}$ & . &.,$I T Y$ & .699. & $\begin{array}{c}- \\
.6174\end{array}$ & $\cdots \wedge 0$ & $\cdot \sigma r \leqslant Y$ & - & $\begin{array}{c}- \\
.6100\end{array}$ & $\begin{array}{c}- \\
.6 Y Y Y\end{array}$ & -10 \\
\hline & & 1 & $\cdot 6 \cdot 11$ &.- .694 & $\cdot r \leq 9$ & $.60 \mathrm{~V}$ & $\begin{array}{c}- \\
.6, y\end{array}$ & $\begin{array}{c}- \\
.,|r|\end{array}$ & .6111 & $\begin{array}{c}- \\
. \text {. T० }\end{array}$ & $\cdot . r V$ & $\cdot 6 \cdot r q$ & $\begin{array}{c}- \\
.61 Y V\end{array}$ & $\begin{array}{c}- \\
.61 \vee 7\end{array}$ & $\begin{array}{c}- \\
., r Y r\end{array}$ & $\begin{array}{c}- \\
.6 . \wedge V\end{array}$ & $.6,1 r$ & -17 \\
\hline & 1 & $\cdots v$ & $\begin{array}{c}- \\
.6 .09\end{array}$ & $\cdot 6 \cdot 7$. & $\cdot r_{0}$ & $\cdot 6 \leqslant \Lambda$ & $\begin{array}{c}- \\
.61 \times 9\end{array}$ & .609 & 1.61 & $\begin{array}{c}- \\
.61 \wedge \varepsilon\end{array}$ & $.61 \leq 9$ & $\begin{array}{c}- \\
.61 \cdot 7\end{array}$ & .6171 & $.6 Y \leq 1$ & $\begin{array}{c}- \\
.6 \cdot 1 r\end{array}$ & $\begin{array}{c}- \\
.6 .71\end{array}$ & E & $-1 V$ \\
\hline 1 & $\begin{array}{r}- \\
.6 Y \Psi \varepsilon \\
\end{array}$ & $\cdot 6 \wedge 9$ & $\begin{array}{c}- \\
.6 .09\end{array}$ & צדז, .- & $\cdot 6 \leq \leq \leq$ & . 6Y11 & .60. & $\begin{array}{c}- \\
.6174\end{array}$ & $\cdot \quad 1 \leq r$ & .610 & $\begin{array}{c}- \\
.6 \cdot V \varepsilon\end{array}$ & $\cdot .1 \leqslant V$ & .6111 & $\begin{array}{c}- \\
.6 \mid Y_{1}\end{array}$ & $\begin{array}{c}- \\
.6 .01\end{array}$ & E & .6 .01 & -11 \\
\hline
\end{tabular}

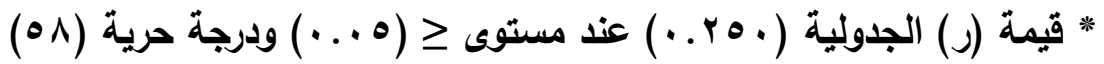

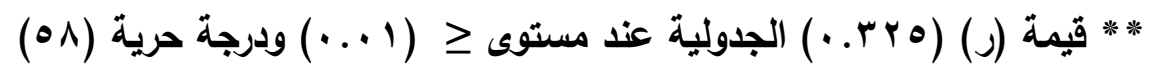


ع - ا-ب التحليل العاملي لاختبارات عناصر اللياقة البدنية الخاصة :

ع-1-r-1 الجذور الكامنة ونسب التباين والتباين المتجمع للعوامل :

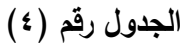

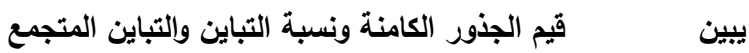

\begin{tabular}{|c|c|c|c|}
\hline التباين المتجمع & نسبة التباين & قيم الجذور الكامنة * & ت \\
\hline 14.419 & $1 T .419$ & T. T৭V & 1 \\
\hline rE.TrT & سוr. & T..rT & r \\
\hline TE.VY) & $1 \cdot \ldots 19$ & 1.117 & r \\
\hline$\varepsilon \varepsilon . Y Y V$ & 9.0 .7 & 1.211 & $\varepsilon$ \\
\hline OY.ATo & $1.7 \cdot 1$ & 1.00 & 0 \\
\hline I. . YAr & $V . \varepsilon \leqslant V$ & $1 . r \leqslant 1$ & 7 \\
\hline 77.498 & $7 .+1 \leqslant$ & מה... & V \\
\hline VI. $\leqslant 0$. & $0.10 \pi$ & $.9 Y \wedge$ & $\wedge$ \\
\hline V7.171 & $\varepsilon . \vee 1 \wedge$ & $\cdot . \wedge \leq 9$ & 9 \\
\hline$\wedge . . \vee \vee \varepsilon$ & $\varepsilon .7 .7$ &.$\wedge r q$ & 1. \\
\hline$\wedge \leqslant .0 \leqslant 1$ & T.VTV &. $.7 \vee \wedge$ & 11 \\
\hline NV.9Ir & r.rv. & $\cdot .7 \cdot V$ & Ir \\
\hline $91 . .0 \mathrm{~V}$ & $r .1 \leq 0$ & .077 & M \\
\hline 94.710 & $r .001$ & $\cdot . \leqslant 7$. & $1 \varepsilon$ \\
\hline $90.19 \leq$ & T. TVQ &..$\leqslant 1$. & 10 \\
\hline $9 \vee . \vee 9 \wedge$ & $1.9 \cdot \varepsilon$ & . & 17 \\
\hline $99 . r \leq 1$ & $1.0 \leqslant \varepsilon$ &. TVA & iv \\
\hline$\ldots \ldots$ & .709 & .119 & 11 \\
\hline
\end{tabular}

الجدول (ع) ييين أن قيم الجذور الكامنة التي نزيد عن الواحد الصحيح أو تساويه عددها ست

قيم، وهذا يعطي مؤشراً على عدد العوامل المستخلصة والمقبولة في هذه الدراسة. (فرج، • 191 ، هبr)

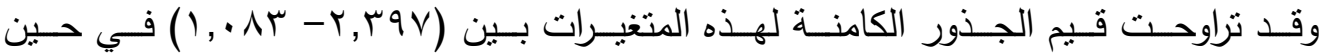

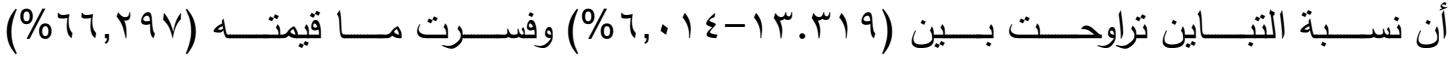

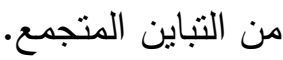

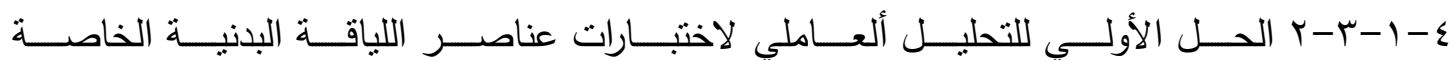
(قبل التدوير) : 
الجدول رقم (•) - (ه)

مصفوفة العوامل قبل التدوير لاختبارات عناصر اللياقة البنية الخاصة

يبين

\begin{tabular}{|c|c|c|c|c|c|c|c|c|}
\hline \multirow[b]{2}{*}{ الشيوع } & \multicolumn{7}{|c|}{ العوامل } & \multirow[b]{2}{*}{$ت$} \\
\hline & العامل السابع & السادس & الخامس & الرابع & الثالث & الثاني & العامل الأول & \\
\hline $.07 r$ & - & $\cdot . \leqslant \leqslant 0-$ & .979 & & $\because 1$ Vo & $. .77-$ & r & 1 \\
\hline$\because \vee \backslash \wedge$ & 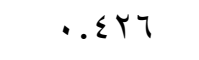 & $\cdots \cdot 1-$ & .0 .9 & $\cdots 99$ & . r. & $\cdot r \cdot v$ & $. Y \wedge \leq$ & r \\
\hline $.00 r$ & $. r \leqslant V$ & $\cdot . Y V Y-$ & ...YY- & $. Y 17-$ & $\cdot . \cdot Y-$ & $.0 \mathrm{VT}$ & .170 & $r$ \\
\hline $.7 \leq 1$ & $. .197-$ &..$V r$ & $. .991-$ & $.1 \cdot 7$ &. $.09 r$ & . . &.$Y I V$ & $\varepsilon$ \\
\hline .794 & . . $\leqslant \leqslant .-$ & $\cdots r$ &.$|Y|$ & . EYr & $.11 \leq$ &. .011 & $\because \mid \vee \wedge$ & 0 \\
\hline$\because \leqslant \wedge 9$ & .119 & $\cdots \vee V \varepsilon-$ & $\ldots \vee v \leqslant-$ & $. . r v ו-$ & $\cdots 17$ &.. $\mid \vee \wedge-$ & $.04 \wedge$ & 7 \\
\hline $.7 Y 7$ & $. r \leq r$ & $.19 r$ &.$r 79$ & $\cdot \varepsilon 7$. & $. .01-$ &. ror & $. r \leq r-$ & v \\
\hline$\because \vee \leq q$ & $. .999-$ & $\cdot . \leqslant O V$ & $\cdot . \leqslant \vee 7$ & . $. M T \leqslant-$ &..$\leqslant Y !$ & $. .1 \leq 0$ & ..rq- & $\wedge$ \\
\hline. .091 &. Y0T &. .YI & $\cdot . Y \leq 1-$ & $\because \varepsilon V Y$ &. . КА५- & . IIV & $\cdots 1$ & 9 \\
\hline. .779 &. $\mid 11$ &. .09 & $\because \leqslant \wedge q$ & $. r \leq q$ & דמז. &.$\Sigma \Sigma T$ - & $.1 \vee 9-$ & 1. \\
\hline$\cdot \wedge \leqslant \wedge$ & .ror & $\cdots \wedge \wedge$ & $. .109-$ & $\cdots \leqslant 7$ & $\cdot \varepsilon \cdot \Gamma$ & $. r \leqslant 0-$ &.$V Y T$ & 11 \\
\hline . . & r & $\cdot 1 \leq V$ & $. .1 \Gamma \cdot-$ & $\cdot r \cdot T$ & $.19 \leq$ & $\cdot . r \cdot Y-$ & .Arr & ir \\
\hline .701 & ...r人- & .MIV &.$|Y|$ &.$\Pi \wedge \varepsilon$ &.$\| M V$ & $. .091-$ & $\cdot 1 \cdot r-$ & IT \\
\hline $.0 \leq 9$ & תTr. & $. .+r \leqslant-$ & $.1 \vee 99-$ &. $\mid 1 \wedge-$ & $\because T \leq$. & $. .1 \leq \leqslant-$ & $. .001-$ & $1 \varepsilon$ \\
\hline$\because v \leq q$ & $\cdots \varepsilon \cdot-$ & $.71 \mathrm{~V}$ & $\cdot . \leqslant \leq \cdot-$ & $\ldots \cdots 7-$ & $\because I V V$ & $. r \leq q$ & $.1 \leq r-$ & 10 \\
\hline $.7 T V$ & $. .110-$ & ..7r & $\cdot . \varepsilon \cdot 9-$ & &..$\leqslant \leqslant r-$ & . & $\cdots 0$ & 17 \\
\hline .700 & .117 & $. . r q \vee-$ & . &. .019 & .ro. & $\because 1 Y 9$ & $. . M r-$ & IV \\
\hline. $.79 V$ & .YYT- &.$r T$. &.$r 91$ & $\cdots 71$ & $.0 Y .-$ & $\cdots+Y_{1}$ & $\cdot . \Sigma T Y-$ & 11 \\
\hline $11.9 r r \leq 0$ & $1 . .1 Y 09 \varepsilon$ & $1 . r \leq .0 Y T$ & $1.0 \leq 901 \pi$ & 1.81 .997 & $1.117 .9 \mathrm{~V}$ & r...rדrq) & $r . r q \vee \leqslant r_{0}$ & * \\
\hline 77.19795 & $7 . .1 \leq \leqslant 11$ & $\vee . \varepsilon \leqslant V \Gamma \leqslant \Lambda$ & $\Lambda .7 \cdot \Lambda \varepsilon .0$ & 9.0 .0040 & $1, . \wedge \wedge \leq r$ & M.r & $1 \pi .419 . \Lambda$ & ** \\
\hline
\end{tabular}

*** نسبة التباين ألعاملي الكفسر الذي يثير إلى أهمية العامل.

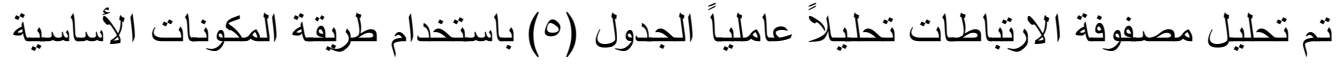
لهوتلنج (hotling principle components) التي تعد من أفضل الطرائق المستخدمة في التحليل

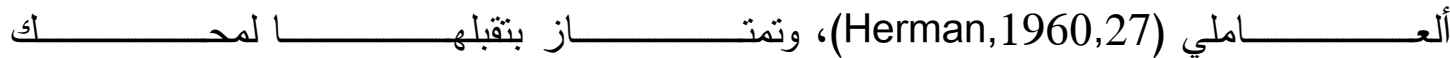
هنري كايزر (H-Kaisar) الذي اقترحه (Gutman) وهو محك يوقف استخلاص العوامل التي يقل

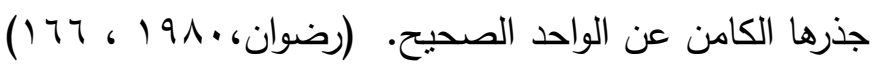


وقد خلص التحليل العاملي إلى سبعة عوامل كما في الجدول (0)، وهي نتائج مباشرة للتحليل وبما أن الحلول المباشرة التي نتوصل إليها من تحليل إلى أخر تثؤدي بنا إلى عوامل معينة فقد تختلف

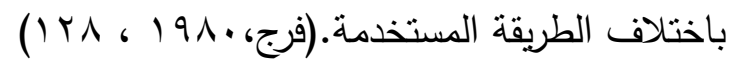

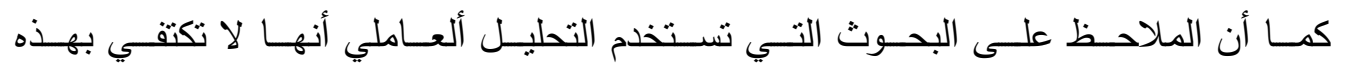

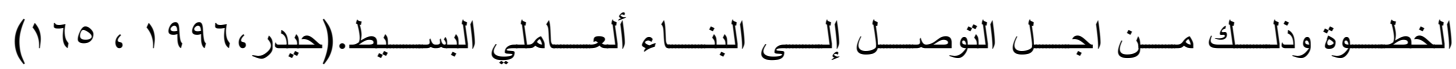

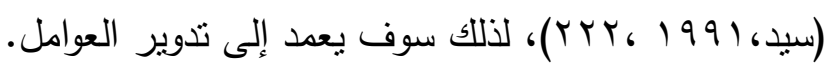

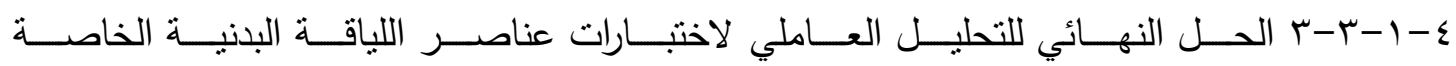

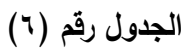

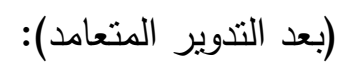

يبين مصفوفة العوامل بعد التدوير لاختبارات عناصر اللياقة البدنية الخاصة

\begin{tabular}{|c|c|c|c|c|c|c|c|c|}
\hline \multirow[b]{2}{*}{ الثيوع } & \multicolumn{7}{|c|}{ العوامل } & \multirow[b]{2}{*}{$ت$} \\
\hline & العامل السابع & السادس & الخامس & الرابع & الثالث & العامل الثاني & العامل الأول & \\
\hline $.07 r$ &. $.7 r$ & $.0 \leqslant T-$ & $\cdot .291$ & $. .0 \leqslant-$ & $. .1 \leq$ & צחו. & $. .1 r-$ & 1 \\
\hline$\cdot \vee \backslash \wedge$ & .71 & $. r \leqslant V-$ & $. .11 V-$ &. .171 &.$r \wedge \varepsilon$ & . YYA - &. .10 & r \\
\hline $.00 r$ & .0174 & ...rI - & ..or &. .911 & $\ldots \leqslant 9-$ & $\cdot v 1 \cdot-$ & $\ldots v$ & $r$ \\
\hline$. .7 \leqslant \Lambda$ & $. .09-$ & .rYq & $.7 r q$ & $. Y 9 \leq$ & $.|v|-$ & $.100-$ & $. . Y \leq 1$ & $\varepsilon$ \\
\hline .794 & .110 & $\cdots \leqslant 0$ &.$v \vee V I$ & דזי.. &. YOV & $\cdots \wedge \wedge-$ & $. .99 .-$ & 0 \\
\hline$\cdot . \leqslant \wedge 9$ & . . Yฯร - & $. .99-$ &.$r 00$ &. .07 & $. .1 \leq \Lambda$ & $\cdot . r \cdot V-$ & $.0 Y 7$ & 7 \\
\hline דודות & $. V Y \leq$ & זד •.. & $\ldots \wedge 1$ &. .00 & $. .99-$ & .1 ro & .ror - & v \\
\hline$\because \vee \leqslant q$ & $. .+11-$ & .11 & $\cdot . \cdot \leq \varepsilon$ & . .ATI &..$\wedge r$ & . & ..r. & $\wedge$ \\
\hline. .091 & .049 & ש &. . & . &. $.1 \cdot 7$ & $. .7 \cdot-$ & $\cdots \wedge$ & 9 \\
\hline. .779 &.$r O \Lambda$ & . ror - & $. .01-$ & $. M I \leq$ & . IIY - &. $.0 V Y$ &. .01 & 1. \\
\hline$\cdot . \wedge \leq \wedge$ & ..or - & $\cdots v$ & $. .0 \leqslant$ & $\cdots \leqslant 7$ & ...r4 - & $\cdots \times 1$ &. $.91 r$ & 11 \\
\hline. . Aor &. .11 & $\cdots 19$ & $. .1 \leq \varepsilon$ & $. .990-$ & $.+10-$ & $.011 r$ & $\cdot . \wedge \vee \leq$ & ir \\
\hline. .701 &..$\wedge V$ & ...rA - & $\ldots \leqslant r-$ & $\ldots \leqslant 1-$ & $\ldots \leqslant$ & .var & $.1 \cdot 7$ & ir \\
\hline $.0 \leq 9$ & $\ldots 19-$ & .01 .0 & $. .191-$ &. .991 & $. .701-$ & $.1 Y \varepsilon$ & .r... - & $1 \varepsilon$ \\
\hline$\because v \leq q$ &..$r \Lambda$ & $. \wedge \leqslant 1$ &. lor &..$\times 1$ & $. .1 .7-$ & $\ldots .1-$ & ..ro - & 10 \\
\hline.$T Y V$ & .. & .0117 & $. .1 \cdot v-$ & $. .791-$ & .100 & 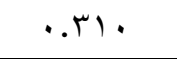 &.. $\mid r-$ & 17 \\
\hline .700 & . ror & $. .1 \times 0-$ & $\therefore \leqslant r q$ & $. .491-$ & $.0 \ldots-$ & $\cdots 7 \cdot-$ &..$I V T$ & IV \\
\hline. $.79 V$ &..$V r$ & .. ro & $\cdots \cdot 1-$ & $\cdots \leqslant V$ &. . Aro & $\because \cdot \leqslant V$ & $\cdots \wedge r$ & 11 \\
\hline 11.9rr & $1 . \leqslant 0 V$ & $1 . \leqslant \wedge \leqslant$ & 1.74. & $1.70 \leq$ & $1 . \vee \wedge T$ & 1.1 .7 & $r .117$ & $*$ \\
\hline 77. 7979 & 1..9V & $\Lambda . r \leq r$ & $9.0 \mathrm{~V}$ & 9.119 & $9.94 r$ & $1 . . . r 0$ & 11. vor & $* *$ \\
\hline
\end{tabular}

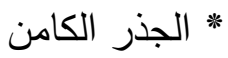

| نسبة التباين ألعاملي الدفسر الذي يثير إلى أهمية العامل. 
من الجدول (T) الذي يمثل نتائج التنوير المتعامد بطريقة تعظيم التباين، نلاحظ التغير في قيم

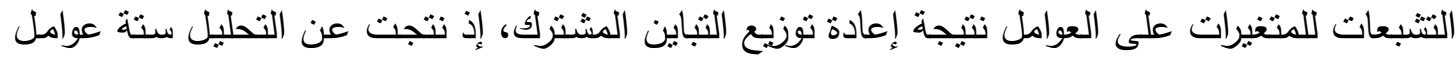

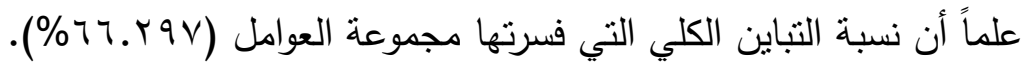
ع-1-ع شروط تفسير العوامل :

اعتمد الباحث في تفسير العوامل الثروط الاتية:

- يقبل العامل الذي يتثبع عليه ثلاثة اختبارات دالة في الأقل، ويعتمد تقسير العوامل في هذا البحث

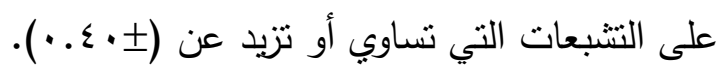

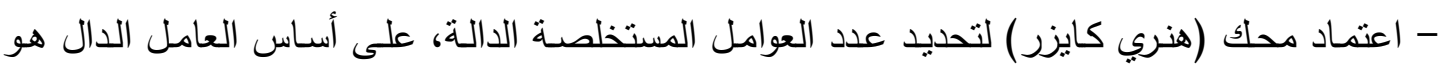
العامل الذي يساوي جذره الكامن واحداً صحيحاً في الأقل.

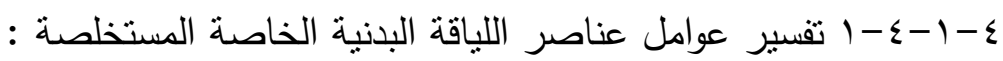

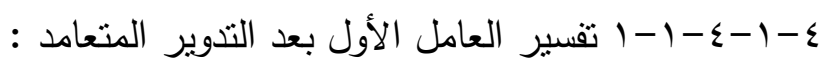

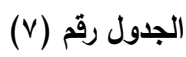

بيين تثبعات الاختبارات بالعامل الأول بعد التدوير المتعامد

\begin{tabular}{|c|c|c|}
\hline التشبع & اسم الاختبار & رقم الاختبار \\
\hline. $.91 \%$ & ركض • ب متر & 11 \\
\hline$\cdot . \wedge \leqslant V$ & ركض • • منز & Ir \\
\hline . & الجري المكوكي (ع××1) م & 7 \\
\hline
\end{tabular}

يبين الجدول (V) المتغيرات التي تشبعت على العامل الأول باستخدام التدوير المتعامد وبقيمة

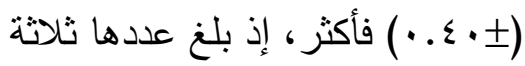

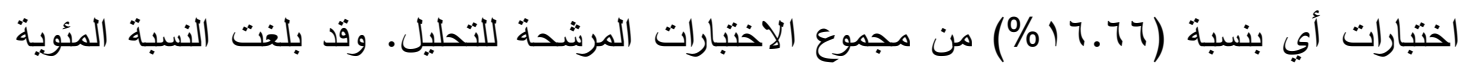
للتباين ألعاملي المفسر لهذا العامل (1,VOF

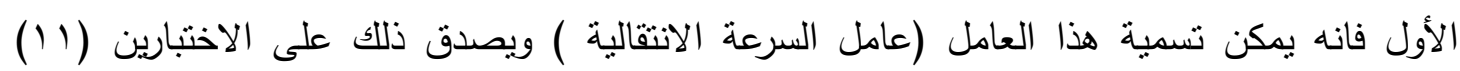

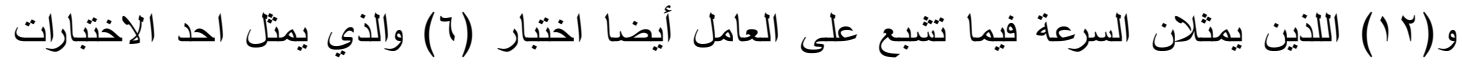
المرشحة عن الرشاقة

إن الصفة الميزة لهذا العامل هي الركض السريع لقطع مسافة الاختبار مع ملاحظة

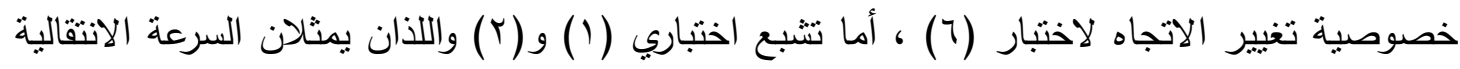
فان ذلك يعود إلى طبيعة تكوين صفة الرشاقة التي تعد صفة طائفية تثمل في تركيبها على العديد من

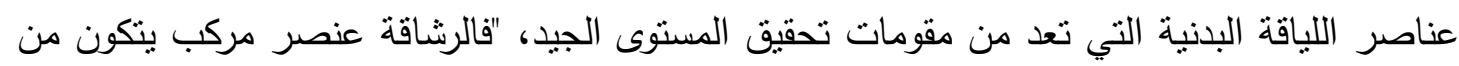

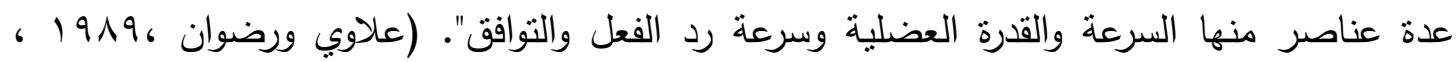
. (YVY وتظهر حاجة لاعب كرة اليد إلى السرعة الانتقالية من خلال حركاته داخل حدود الملعب وإشغاله

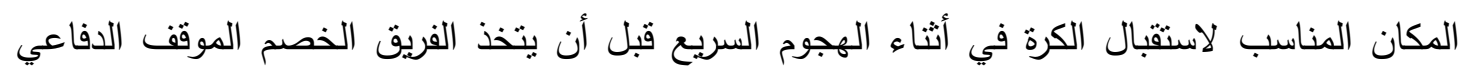


المناسب، وكذللك يكون اللاعب بحاجة إلى السرعة الانتقالية التي تمكنه من الرجوع إلى المنطقة

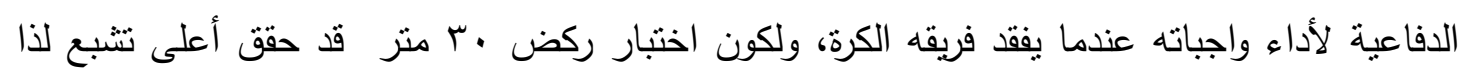
فانه يعد من الاختبارات المرشحة لتمثيل هذا العامل في بطارية اللياقة البدنية الخاصة.

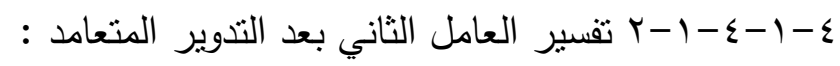

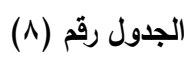

يبين تشبعات الاختبارات بالعامل الثاني بعد التدوير المتعامد

\begin{tabular}{|c|c|c|}
\hline التشبع & اسم الاختبار & رقم الاختبار \\
\hline.$v 9 r$ & الققز العمودي & ir \\
\hline$\cdot . \vee 1 \cdot-$ & الركض بالمواجهة والظهر لمسافة ror r r & r \\
\hline. $.0 V Y$ & ركض •r متر & 1 . \\
\hline
\end{tabular}

يبين الجدول (^) المتغيرات التي تشبعت على العامل الأول باستخدام التدوير المتعامد وبقيمة (أكثر ، إذ بلغ عددها ثلاثة اختبارات

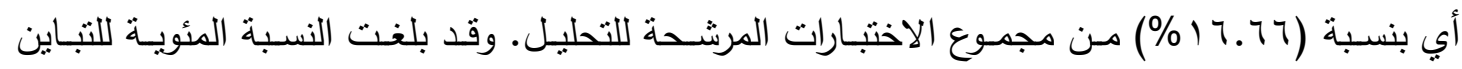

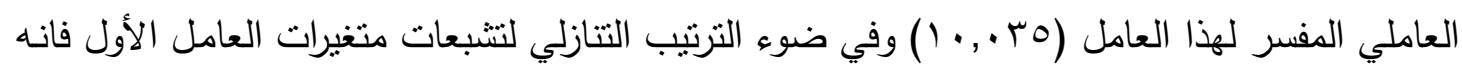
يمكن تسمية هذا العامل (عامل القوة الانفجارية للرجلين ) ويصدق ذلك على اختبار (س ()/الذي بمثل القوة الانفجاريـة للرجلين فيما تشبع على العامل أيضـا اختبار (r) والذي يمثل اختبار مطاولة السرعة

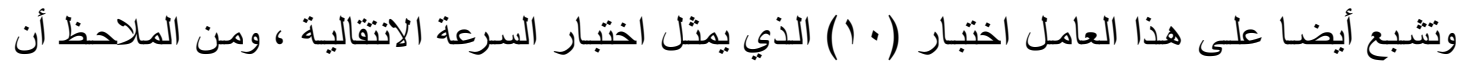
متغيرات اللباقة البدنية جميعها التي حققت أعلى التشبعات على هذا العامل تمتاز بقوة وتحمل الأداء وسرعته والصفة المميزة لهذه الاختبارات هي بذل أقصى قوة بأسرع ما يمكن للتغلب على مقاومة وزن لأن

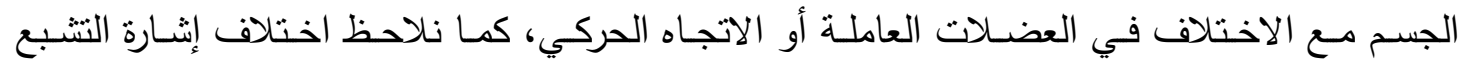

لاختبار الركض بالمواجهة والظهر (ب) وهذا بعود إلى طبيعة الأداء الأفضل على هذا الاختبار .

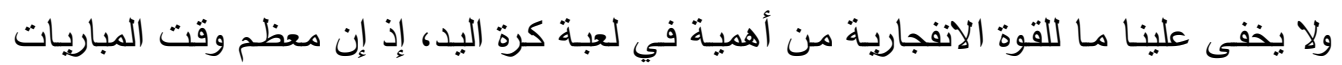

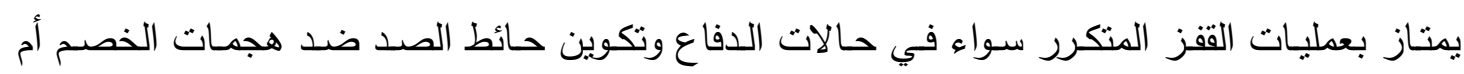

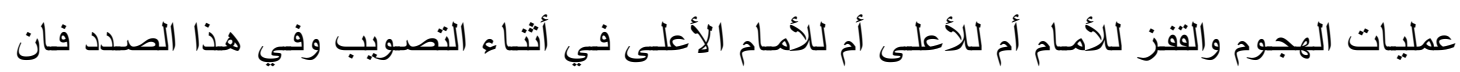

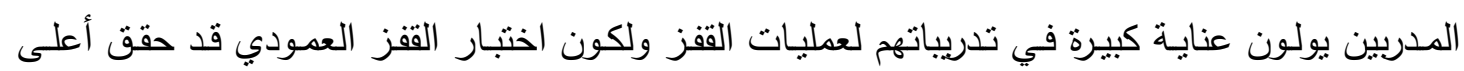
تشبع لذا فانه يعد من الاختبارات المرشحة لتمثيل هذا العامل في بطارية اللباقة البدنية الخاصة. ع - - - -1-r تفسير العامل الثالث بعد التدوير المتعامد : 
(9) الجدول رقم (9)

يبين تثبعات الاختبارات بالعامل الثالث بعد التدوير المتعامد

\begin{tabular}{|c|c|c|}
\hline التشبع & اسم الاختبار & رقم الاختبار \\
\hline.$v 9 r$ & رمي كرة طبية .، غرام بذراع واحدة & 11 \\
\hline$\cdot . \vee 1 \cdot-$ & القزز العريض & $1 \varepsilon$ \\
\hline. $.0 V Y$ & رمي كرة طبية r كغم من الوقوف & iv \\
\hline
\end{tabular}

土ينين الجدول(9) المتغيرات التي تشبعت على العامل الثالث باستخدام التدوير المتعامد

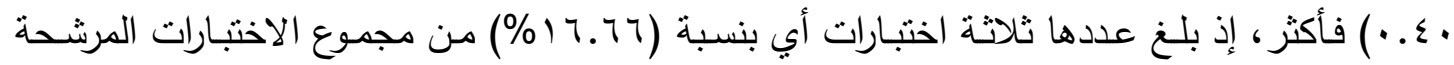

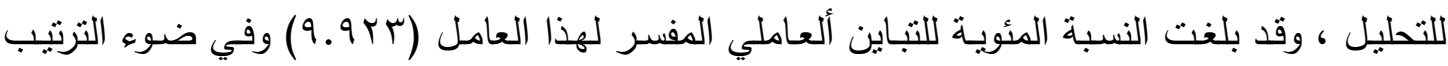
التتازلي لتشبعات متغيرات العامل الثالث فانه يمكن تسمية هذا العامل (عامل القوة الانفجارية للذراعين )

وان الصفة المميزة لهذه الاختبارات هو بذل أقصى قوة بأسرع ما يمكن ضد الأداة المقذوفة ، وان ألأداء

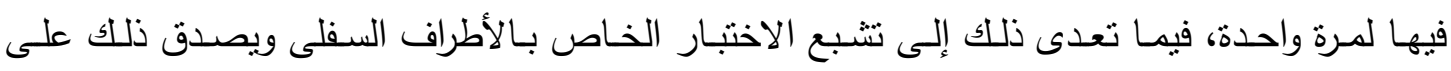

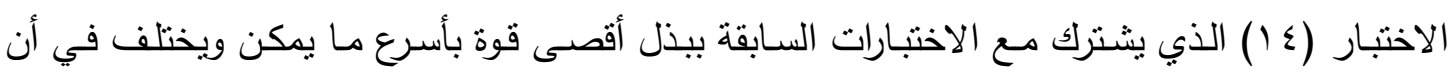
ألأداء لا يكون ضد الأداة المقذوفة وإنما عن طريق المسافة التي يقفزها ، ويرى الباحثون أن خصوصية هذا العامل تتركز في الأطراف العليا وان دخول اختبارات الطرف السفلي ناتج عن كون هذه الاختبارات تمثل القوة السربعة وان انخفاض قيمة التتبع للأطراف السفلى يعطي خصوصية اكبر لهذا العامل وهو ناتج عن اختلاف أجزاء الجسم ، ولابد من الإشارة بأننا حين نتكلم عن القوة في كرة البد فإننا غالباً ما نقصد القوة السريعة لطبيعة اللعبة، ويتفق معظم العاملين في مجال الإعداد البدني على أن صفة القوة واحدة من أهم الصفات البدنية ويمكن الإثـارة إلى انه لا يمكن تطوير مسافة الرمي ما لم تتطور القوة العضلية للذراعين والجذع والرجلين، وان حصل تطور في القوة الخاصة فانه نطور نسبي قياساً بالتطوير الخاص المبني على التطور العام للقوة ولا تخلو أيسة لعبة أو فعالية رياضية من احد أنواع القوة التي

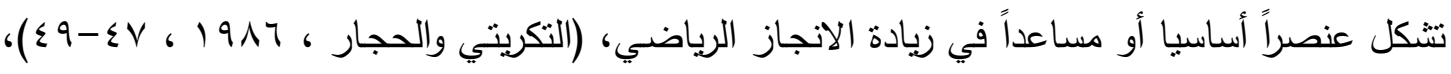
ولكون اختبـار رمسي كرة طبيـة ( . . ) غرام بذراع واحدة ، قد حقق أعلى تشبع لذا فانـه يعد من الاختبارات المرشحة لتمثيل هذا العامل في بطارية اللياقة البدنية الخاصة . الترة

צ - 1 - - - - «تفسير العامل الرابع بعد التدوير المتعامد :

الجدول رقم (·)

يبين تشبعات الاختبارات بالعامل الرابع بعد التدوير المتعامد

\begin{tabular}{|c|c|c|}
\hline التشبع & اسم الاختبار & رقم الاختبار \\
\hline.$\wedge M_{1}$ & الجلوس من الرقود مع مد الرجلين (• ( ) ثانية & $\wedge$ \\
\hline$. .791-$ & رمي كرة طبية r كغم من الجلوس & 17 \\
\hline
\end{tabular}




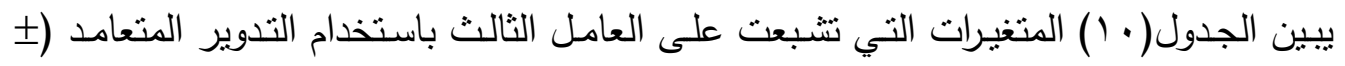

• ع. •) فأكثر، إذ بلغ عددها اختبارين أي بنسبة (1) (1 (1\%) من مجموع الاختبارات المرشحة للتحليل .

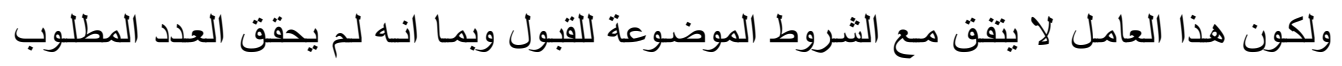

للاختبارات المتشبعة وفقاً للتدوير المتعامد لذا تم إهماله وعدم تمثنله في البطارية المنشودة.

ع - - - - -10 تفسير العامل الخامس بعد التدوير المتعامد :

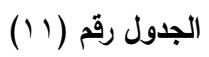

يبين تثبعات الاختبارات بالعامل الخامس بعد التدوير المتعامد روم

\begin{tabular}{|c|c|c|}
\hline التشبع & اسم الاختبار & رقم الاختبار \\
\hline..$\vee V 1$ & جري الزكزالك بن الحواجز بالأرقام & 0 \\
\hline $.7 r 9$ & 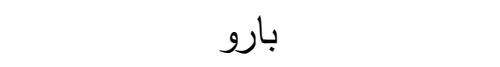 & $\varepsilon$ \\
\hline. .291 & ركض .." متز & 1 \\
\hline..$\leqslant \mu_{q}$ & رمي كرة طبية r كغم من الوقوف & iv \\
\hline
\end{tabular}

يبين الجدول (1 (1) المتغيرات التي تشبعت على العامل الثاني باستخدام التذوير المتعامد وبقيمة

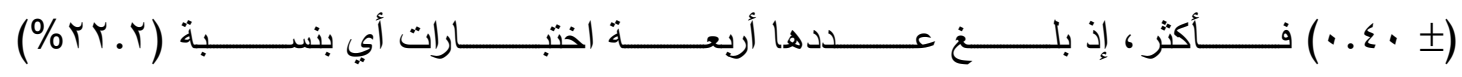
من مجموع الاختبارات المرشحة للتحليل.

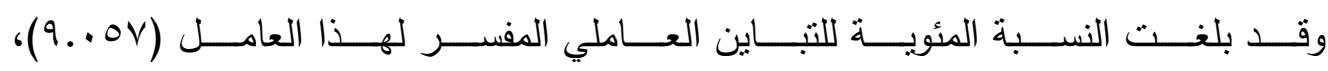

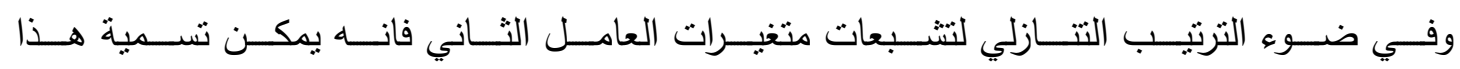
العامل (عامل الرشاقة).

ويصدق ذلك على الاختبارين (0) و (ع) اللذين يمثنان الرشاقة فيما نتبع على العامل أيضا

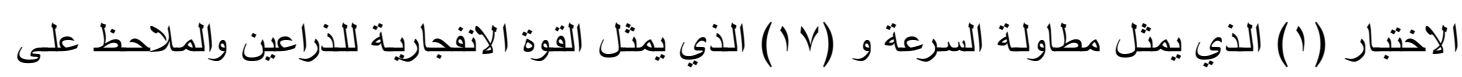

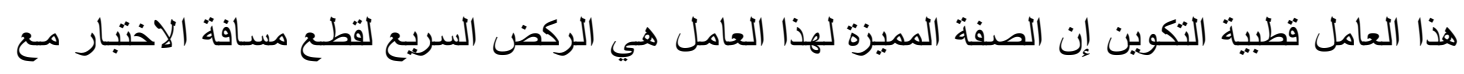
ملاحظة خصوصية تغيير الاتجاه لاختباري (0) (ع)، ، أما فيما يخص الاختبار (1) الذي يماثل هذه

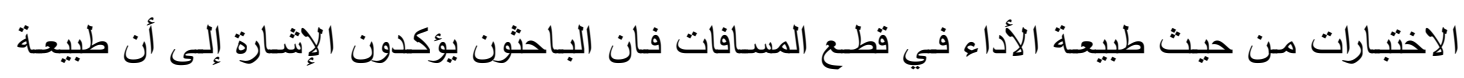

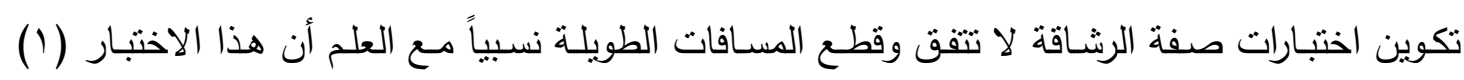
ينفي عنه شرط تغيير الاتجاه و يؤكد الباحثون الإشارة إلى الإيقاع السريع للأداء في لعبة كرة اليد الأمر الئر

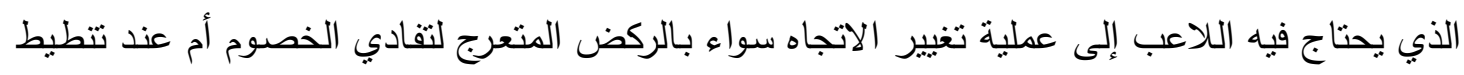
الكرة أم في أثناء الارتداد من الدفاع إلى الهجوم وبالعكس أي من خلال التحرك المفروض وفقاً لاتجاه

ولكون اختبار جري الزكزالك ببين الحـواجز (بالأرقام) قد حقق أعلى تشبع لذا فانـه يعد مـن

الاختبارات المرشحة لتمثيل هذا العامل في بطارية اللياقة البدنية الخاصة.

ع-ب-r-1-1 تفسير العامل السادس بعد التدوبر المتعامد : 


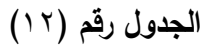

يبين تثبعات الاختبارات بالعامل السادس بعد التدوير المتعامد

\begin{tabular}{|c|c|c|}
\hline التشبع & اسم الاختبار & رقم الاختبار \\
\hline$\cdot . \wedge \varepsilon 1$ & القدرة العودية للوثب (الثشغل) & 10 \\
\hline $.0 \leqslant T-$ & ركض ... ر متر & 1 \\
\hline
\end{tabular}

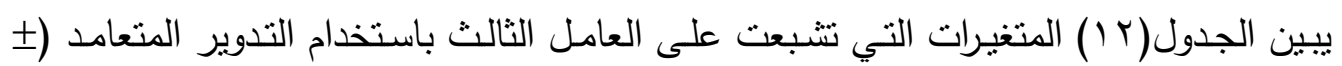

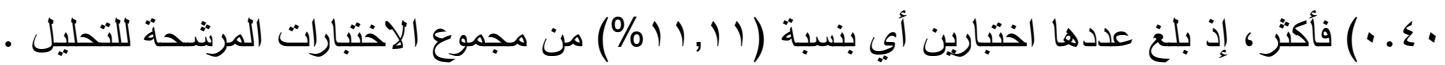
ولكون هذا العامل لا يتفق مع الثروط الموضوعة للقبول وبما انه لم يحقق العدد المطلوب للاختبارات الكتُبعة وفقاً للتنوير المتعامد لذا تم إهماله وعدم تمنيله في البطارية المنشودة.

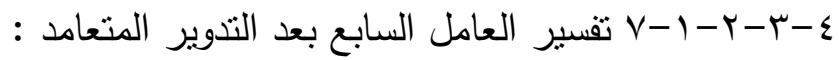

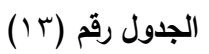

يبين تثبعات الاختبارات بالعامل السابع بعد التدوير المتعامد

\begin{tabular}{|c|c|c|}
\hline التشبع & اسم الاختبار & رقم الاختبار \\
\hline$\cdot V r \leq$ & ثني ومد الذراعين (ثناو)من وضع الانبطاح المائل ا ثا & v \\
\hline$\cdot .71$ & ركض . . ؛ متر & r \\
\hline . .0rq & ثلات وثبات بالقدمين من الثبات & 9 \\
\hline
\end{tabular}

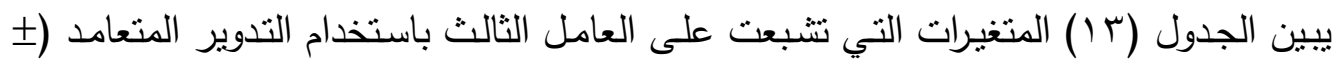

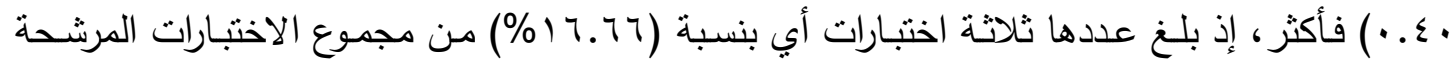
كلتحليل

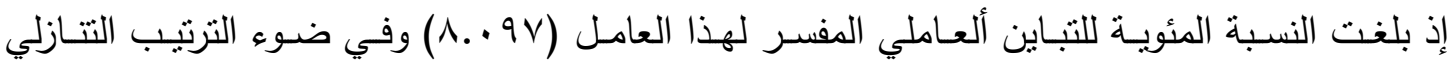

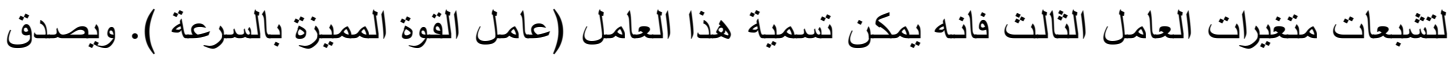

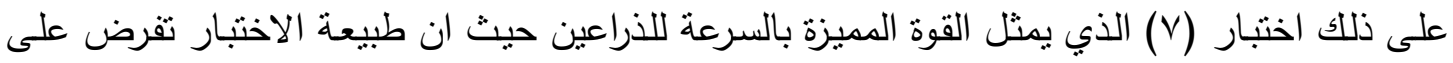

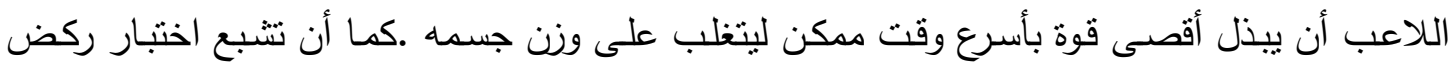

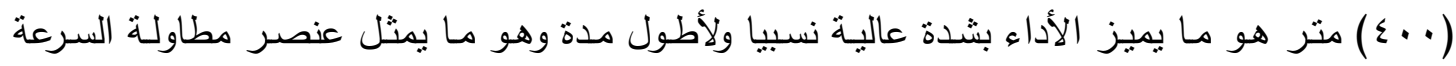

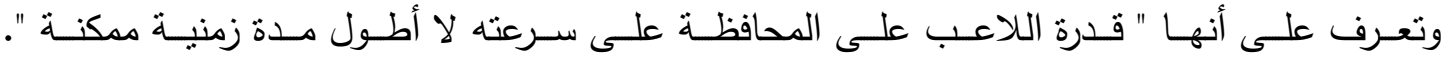

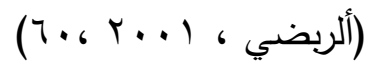

ويعمل اللاعب هنا تحت وطأة الأداء السريع وهذا ما نجده في مباريات كرة اليد من خلال الذهاب في

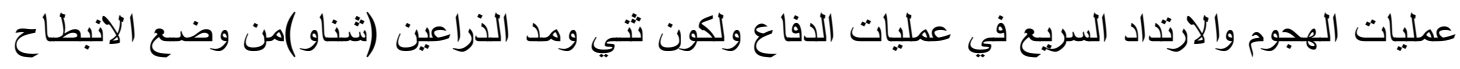

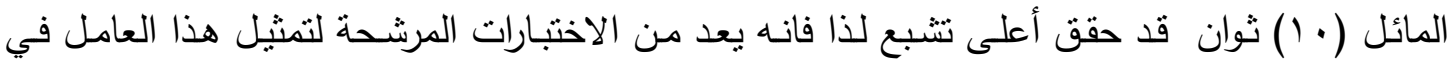
بطارية اللياقة البدنية الخاصة . 
ع-ه البطارية المستخلصة :

تم ترشيح وحدات الاختبـار التي حققت أعلى تشبعات مشـاهدة على عوامـل اللياقـة البدنيـة

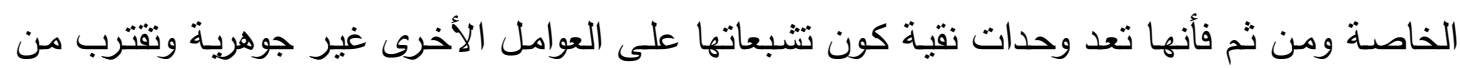

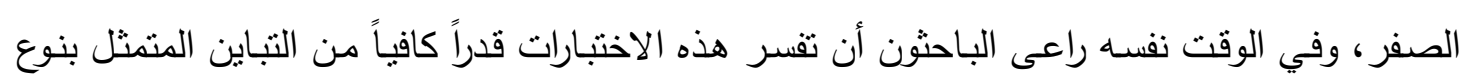
الشيوع الذي يمثل تفسير الأداء لكل اختبار في ضوء العوامل المستخلصة والجداول(ع () و (0) (10) تبين ذلك .

الجدول رقم (ع ( )

يبين الوحدات المرشحة عن عوامل بطارية اللياقة البذنية الخاصة

\begin{tabular}{|c|c|c|c|c|c|c|c|c|c|c|c|}
\hline \multirow{2}{*}{ الثيوع } & \multicolumn{7}{|c|}{ التثبع على العوامل } & \multirow{2}{*}{ اسم الاختبار } & \multirow{2}{*}{ |لاختبار } & \multirow{2}{*}{ 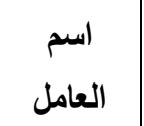 } & \multirow{2}{*}{ رقم } \\
\hline & v & 7 & 0 & $\varepsilon$ & $r$ & r & 1 & & & & \\
\hline$\cdot \wedge \leq \wedge$ & ..orr- & $\cdots v$ & $\ldots 0 \leq$ & $\because \cdot \leq 4$ & ...rq- & $\cdots v 1$ & $.91 \%$ & ركض . . " متر & 11 & الانتقالية & 1 \\
\hline. .701 & $\ldots \wedge v$ & $\ldots r \wedge-$ & $\ldots \leq r-$ & $\ldots \leqslant 1-$ & $\cdots \varepsilon \cdot-$ & $\because v q r$ & $\cdot .1 \cdot 7$ & القفز العمودي & ir & الانفجارية & r \\
\hline. $.79 \mathrm{~V}$ & $\ldots v r$ & $\cdots$ ro & $\cdots \cdot 1-$ & $\cdots \leqslant V$ & .Aro & $\cdots \leqslant V$ & $\cdots \wedge r$ & غرام بذراع واحدة طبية . & 11 & |للانفجارية & $r$ \\
\hline. .794 & .110 & $\cdots \leqslant 0$ & $\because \vee \vee 1$ & $\ldots+r 4$ & $\because Y \otimes V$ & $\cdots \wedge \wedge-$ & $\cdots 9 \cdot-$ & 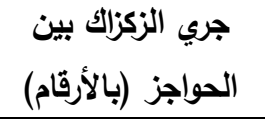 & 0 & الرشاقة & $\varepsilon$ \\
\hline - & $\because V Y \leq$ & מיד & $\cdots \wedge 1$ & $\cdots .00$ & $. .99 r-$ & .1 ro & $\because r \otimes r-$ & ثني ومد الأراعين & v & بالسرعة الميزة & 0 \\
\hline
\end{tabular}

الجدول رقم (10)

يبين الارتباطات البينية لاختبارات بطارية اللياقة البلنية الخاصة المستخلصة

\begin{tabular}{|c|c|c|c|c|c|c|}
\hline$v$ & 0 & 11 & $1 \pi$ & 11 & الاختبارات & الاختبر \\
\hline$. Y 17-$ & $\cdots 11$ &. .00 . & $\ldots 9$. & 1 & ركض . . " متر & 11 \\
\hline. .01 & $\ldots 94-$ & $\ldots \leq \leqslant$ & 1 & & الققز العمودي & ir \\
\hline$\ldots v \varepsilon-$ &. .111 & 1 & & & رمي كرة طبية . . 1 غرام بذراع & 11 \\
\hline$. .1 \leq 1$ & 1 & & & & $\begin{array}{c}\text { جري الزكزالك بين الحواجز } \\
\text { (بالأرقام) }\end{array}$ & 0 \\
\hline 1 & & & & & ثني وضع الانبطاح المائل ـ ـ ثانين (شناو) من & V \\
\hline
\end{tabular}


0 - الاستتتاجات وإلتوصيات :

$$
\text { 0 - 1 - الاستنتاجات : }
$$

أولا :تم قبول خمسـة عوامل وهي (العامل الأول عامل السـرعة الانتقاليـة ، العامل الثاني عامل القوة الانفجارية للرجلين ، العامل الثالث عامل القوة الانفجارية للذراعين ،العامل الرابع عامل الرشاقة ، العامل الخامس عامل القوة المميزة بالسرعة ) ثانياً : العوامل المستخلصة للبطارية هي :

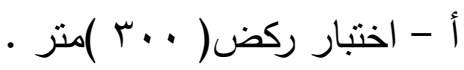

ب - اختبار القفز العمودي •

ج - اختبار رمي كرة طبية ( . (1 )غرام بذراع واحدة .

د - اختبار جري الزكزاك بين الحواجز بالأرقام •

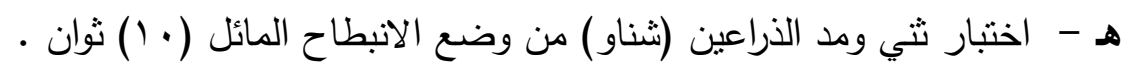

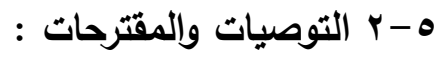

أولا :اسـتخدام بطاريـة اللياقـة البدنيـة الخاصـة في الاختبـارات العمليـة لمعرفـة فاعليـة البرنـامج

$$
\text { التدريبي في نهاية الإعداد البدني الخاص لأندية كرة البد العراقية . }
$$

ثانيا : إجراء دراسات على فئات عمرية مختلفة من الثباب والمتقدمين والنساء .

$$
\text { المصادر }
$$

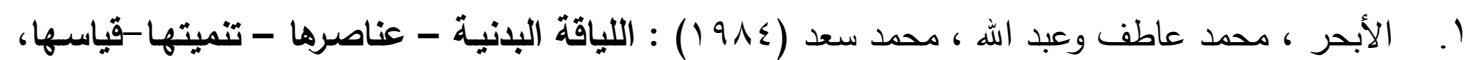

$$
\text { دار الإصلاح، السعودية . }
$$

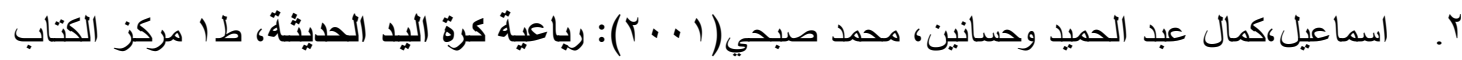

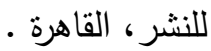

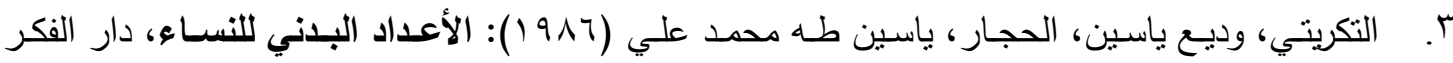

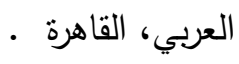

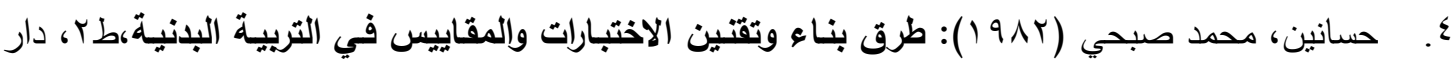

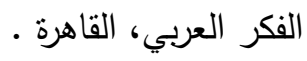

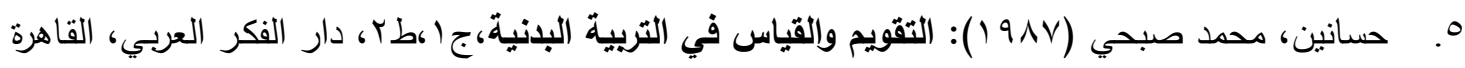

7. حسانين، محمد صبحي (990 ()): القياس والتقويم في التربيـة البلنية والرياضـة، ج(، طس، دار الفكر

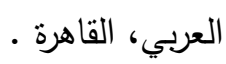

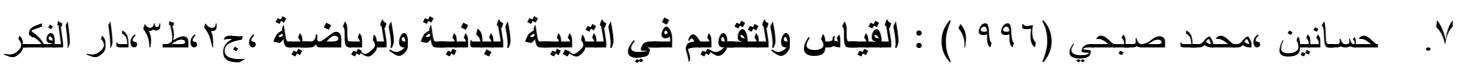

العربي القاهرة .

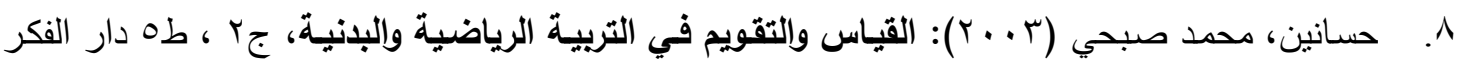

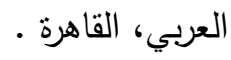




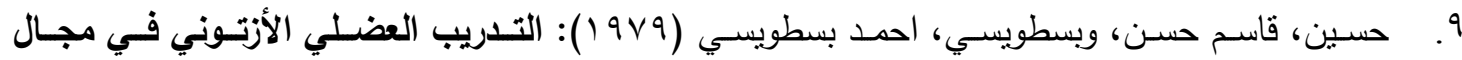

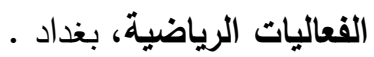

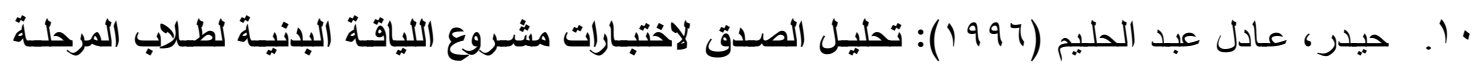
الثانوية بالمحافظة الغربية، مجلة نظريات وتطبيقات كلبة التربية الرياضية للبنين، الإسكندرية .

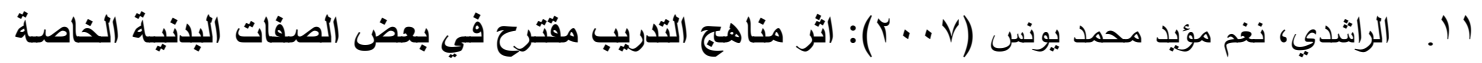

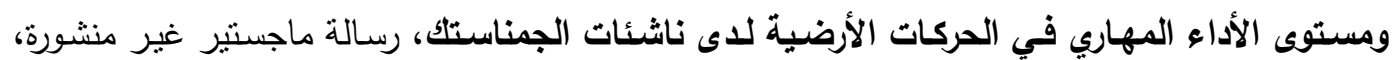
كلية التربية الرياضية، جامعة الموصل .

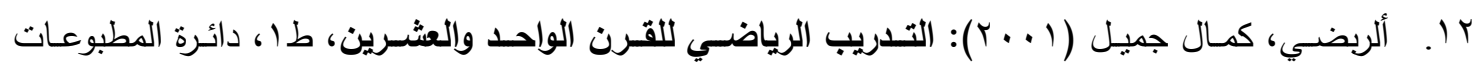
والنشر ، عمان .

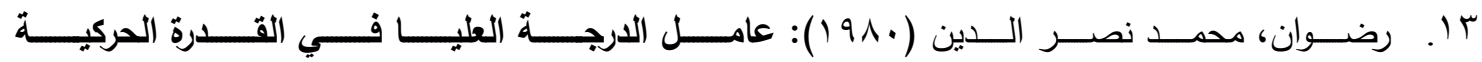

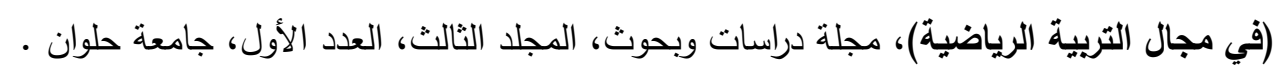

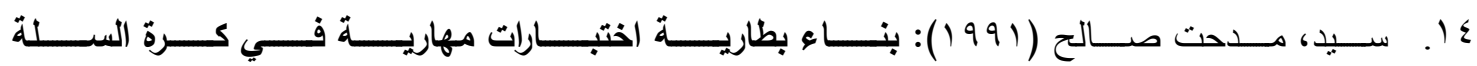
(دراسة عامليه)، مجلة علوم وفنون الرياضية، المجلد الثالث، العدد الأول والثاني، القاهرة.

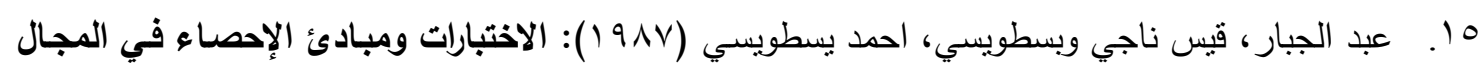

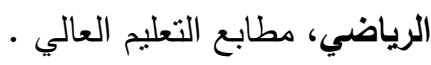
17 1. عبد الفتاح، أبو العلا احمد (99V) (197): التدريب (الأسس الفسيولوجية )، دار الفكر العربي، القاهرة.

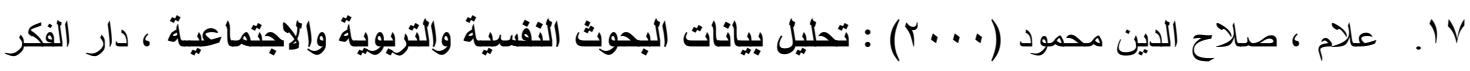

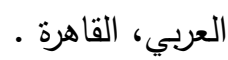

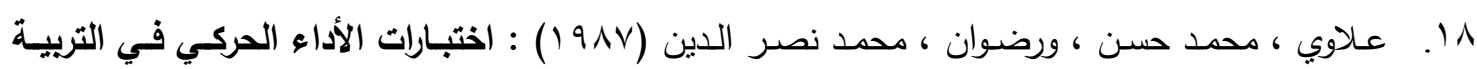

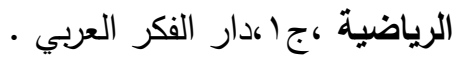
9 19. عـلاوي، محمد حسن ورضوان، محمد نصر الدين (919 (1)): اختبـارات الأداء الحركي، طب، دار الفكر

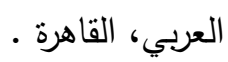

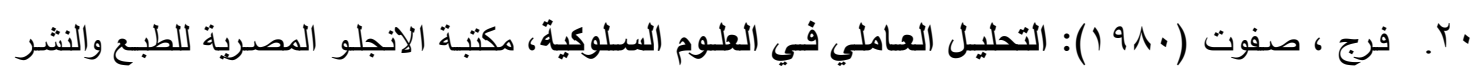
القاهرة .

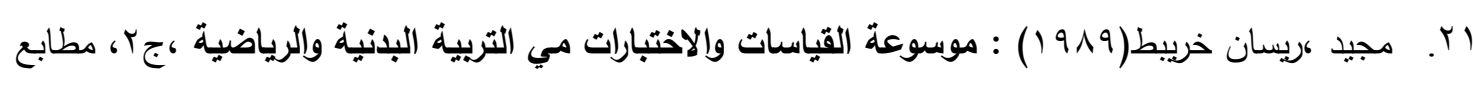

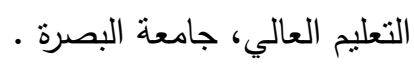

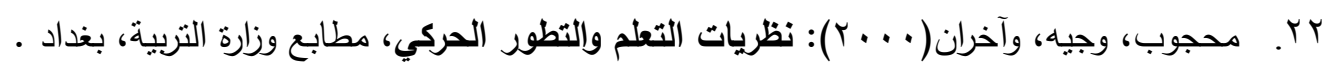

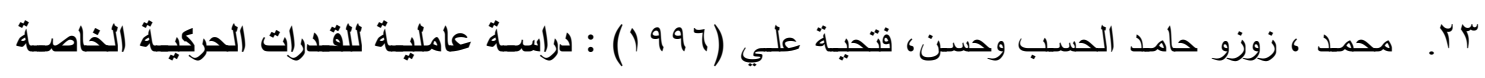

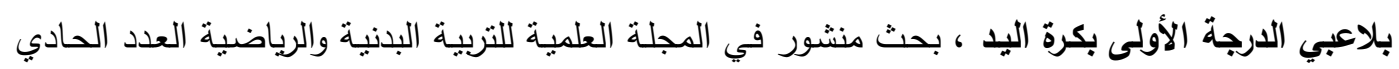
عشر، كلية التربية الرياضة للبنات ، جامعة الإسكندرية .

24. Herman ,H.H ,(1960):Modern factor Analysis, Chicago ,press Chicago university. 


\section{الملاحق}

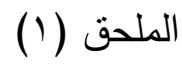

بسم الله الرحمن الرحيم

جامعة الموصل

كلية التربية الرياضية

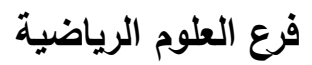

م/ استمارة استيان

الأستاذ الفاضل ..................................................................

يروم الباحثون إجراء البحث الموسوم (التحليل العاملي لعناصر اللياقة البننية الخاصة للاعبي

أندية دوري النخبة بكرة اليد).

وقد قام الباحثون بالمسح الثشامل لعدد من المصادر العلمية المختصة بكرة اليد والقياس والنقويم

لتحديد عناصر اللياقة البدنية الخاصة والاختبارات الملائمة لها.

برجى من سيادتكم بيان رأيكم في:-

ـ عناصر اللياقة البدنية الخاصة للاعبي كرة اليد. ـ ملائمة الاختبارات المقترحة لعناصر اللياقة البننية الخاصة للاعبي كرة اليد. _ إضافة أب عنصر آخر ترونه مناسباً.

ـ ـ إضافة إلى اختبار لأي عنصر من عناصر اللياقة البدنية الخاصة. ولكم جزيل الثكر والتقدير....

الباحثون 
بناء بطارية اختبارات لعناصر الياقة البدنية الخاصة للاعبي..

\begin{tabular}{|c|c|c|c|}
\hline المقترحات & 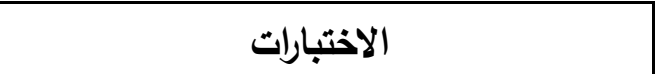 & عناصر اللياقة البذنية الخاصة & $ت$ \\
\hline & 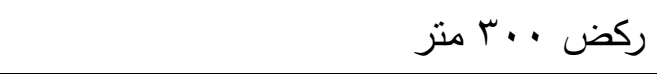 & \multirow[t]{4}{*}{ 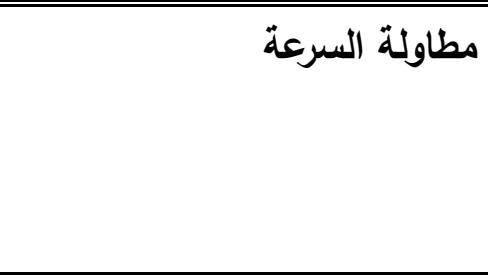 } & \multirow[t]{4}{*}{-1} \\
\hline & ركض ... متر & & \\
\hline & الركض بالمواجهة والظهر لمسافة ror rمتر & & \\
\hline & أى اختبار آخر ترونه مناسباً & & \\
\hline & بارو & \multirow[t]{4}{*}{ 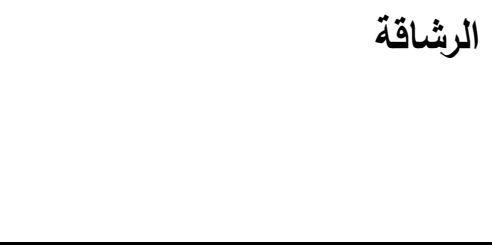 } & \multirow[t]{4}{*}{$-r$} \\
\hline & جرى الزكزاك بين الحواجز بالأرقام & & \\
\hline & الجرى المكوكى & & \\
\hline & أى اختبار آخر ترونه مناسباً & & \\
\hline & ثني ومد الذراعين (شناو) من الانبطاح المائل & \multirow[t]{5}{*}{ القوة المميزة بالسرعة } & \multirow[t]{5}{*}{$-r$} \\
\hline & لمن: & & \\
\hline & الجلوس من الرقود مع مد الرجلين (• (ثا) & & \\
\hline & اختبار ثلاث وثبات بالقدمين من الثبات & & \\
\hline & أي اختبار آخر ترونه هناسباً & & \\
\hline & ركض (•rامتر) & \multirow[t]{4}{*}{ 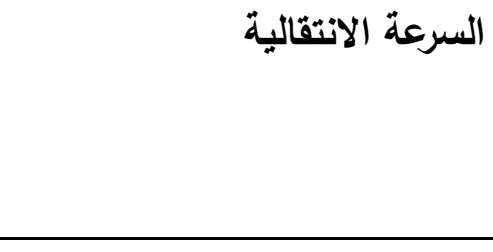 } & \multirow[t]{4}{*}{$-\varepsilon$} \\
\hline & ركض (·"متر) & & \\
\hline & ركض (•عمتر) & & \\
\hline & أى اختبار آخر ترونه مناسباً & & \\
\hline & اختبار القفز العمودي من التبات & \multirow[t]{4}{*}{ القوة الانفجارية للرجلين } & \multirow[t]{4}{*}{-0} \\
\hline & الوثب العريض من الثبات & & \\
\hline & اختبار القدرة العمودية (الثغل) & & \\
\hline & أى اختبار آخر ترونه مناسباً & & \\
\hline & رمى كرة طبية (سكغم) من الجلوس & \multirow[t]{4}{*}{ القوة الانفجارية للذراعين } & \multirow[t]{4}{*}{-9} \\
\hline & رمى كرة طبية من فوق الرأس ــ & & \\
\hline & رمى كرة طبية (.. ـ غر) لأبعد مسافة & & \\
\hline & أى اختبار آخر ترونه مناسباً & & \\
\hline
\end{tabular}


المحلق (r)

اختبارات عناصر اللياقة البدينة الخاصة

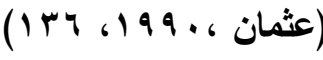

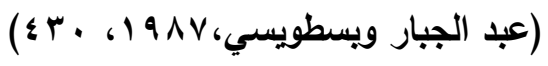

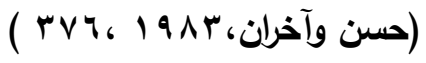

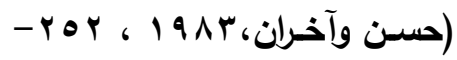

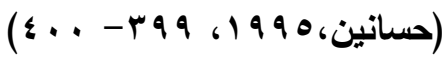

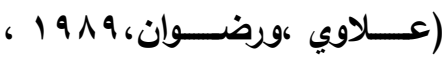

( عبد الجبار ويسطويسي ، و (

( RVY، I 9Ar، ، حسن وآخران)

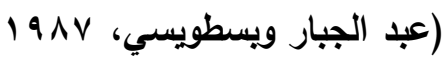

(عــــلاوي ورضــــــوان، 1919 )

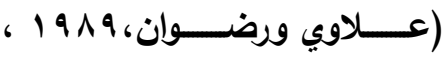

(r ( $)$

(حسانين، (990) 1994 )

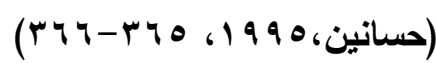

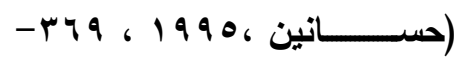

أ- القوة الاتفجارية للذراعين واختباراتها: 1 - رمي الكرة الطبية (ب كفم ) من الجلوس . r - اختبار رمي الكرة الطبية (r كفم) من فوق الرأس.

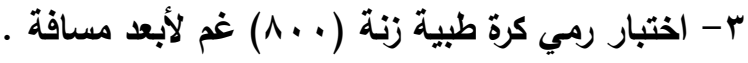
ب - القوة الانفجارية للرجلين واختباراتها : 1 - اختبار القفز العمودي من الثبات.

(ror r - اختبار الوثب العريض من الثبات . r - اختبار القدرة العمودية للوثب (الثغل) من التبات $(9)-\wedge 9$ ج- السرعة الانتقالية واختباراتها :

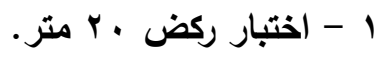

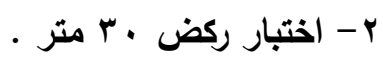

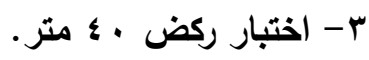

(rTr.

د- مطاولة السرعة واختباراتها :

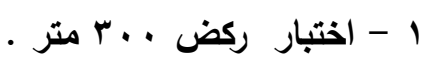

(r). r- اختبار ركض · + . (r).

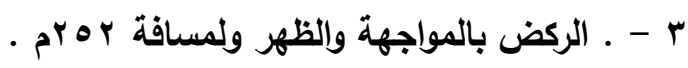

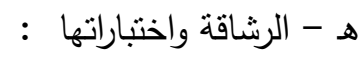

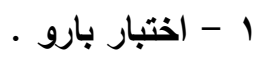

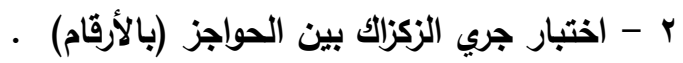
r - اختبار الجري المكوكي ع × • ام . (rv. و - القوة المميزة بالسرعة واختباراتها : 1 - اختبار ثني ومد الأراعين (شناو) من وضع الانبطاح المائل في ( • ()ثا . ( r \&V، I9 VV، عبد الجبارويسطويسي)

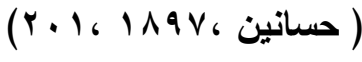
r - اختبار الجلوس من الرقود مع مد الرجلين ( • اثثا) .
( 199 ، 19 19V ، حسانين )

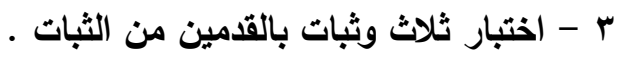

